\title{
LA FISCALIDAD SOBRE EL CARBONO. UNA APROXIMACIÓN A LOS CASOS DE SUECIA, IRLANDA Y FRANCIA ${ }^{1}$
}

\author{
Autores: Macarena Larrea Basterra \\ macarena.larrea@orkestra.deusto.es \\ Orkestra-Fundación Deusto. Universidad de Deusto \\ Jorge Fernández Gómez \\ jorge.fernandez@orkestra.deusto.es \\ Orkestra-Fundación Deusto. Universidad de Deusto \\ Roberto Álvaro Hermana \\ roberto.alvaro@orkestra.deusto.es \\ Orkestra-Fundación Deusto. Universidad de Deusto
}

\section{Resumen}

La lucha contra el cambio climático ha encontrado en la fiscalidad una herramienta para avanzar en la reducción de las emisiones de gases de efecto invernadero. Diferentes países han desarrollado figuras impositivas sobre el carbono en Europa, América o Asia.

${ }^{1}$ Este documento se basa en Larrea Basterra, M.; Fernández Gómez, J.; Álvaro Hermana, R. (2019). La fiscalidad energética en Francia. El impuesto sobre el carbono. Orkestra. Disponible en https://www.orkestra. deusto.es/images/investigacion/publicaciones/informes/cuadernos-orkestra/fiscalidad-energetica-francia.pdf 
En Europa, Suecia estableció un impuesto sobre el carbono hace cerca de tres décadas, Irlanda lo adoptó en el contexto de la crisis económica de 2008 y, más recientemente, Francia alumbró su Ley de transición energética para un crecimiento verde con el apoyo de un impuesto sobre el carbono denominado contribución clima energía.

Las tres experiencias, que han tenido diferentes impactos, pueden aportar luces sobre los factores que pueden favorecer el éxito de estas medidas. Para ello, el presente artículo tiene como objetivo presentar de manera resumida las principales características no solo de los impuestos sobre el carbono, sino también de sus procesos de adopción y del destino de la recaudación obtenida.

Palabras clave: impuesto sobre el carbono; Régimen de Comercio de Derechos de Emisión de la UE; recaudación fiscal; emisiones GEI.

\section{Carbon taxation. An approach to the cases of Sweden, Ireland and France}

\section{Abstract}

The fight against climate change has found in taxation a tool for advancing in the reduction of greenhouse gas emissions. In this regard, different countries have developed taxes on carbon in Europe, America or Asia.

In Europe, Sweden established a carbon tax about three decades ago, Ireland adopted it during the economic crisis of 2008 and, more recently, France accompanied its Law on energy towards a green growth with a carbon tax called energy climate contribution.

The three experiences, which have had different impacts, can bring light on the factors that may favor the success of these measures. To this end, this article aims to present a summary of the main characteristics not only of the carbon taxes, but also of their adoption processes and the destination of the revenues collected.

Key words: carbon tax; European Emissions Trading Scheme; tax collection GHG emissions. 


\section{INTRODUCCIÓN}

La lucha contra el cambio climático ha encontrado en los precios sobre el carbono una herramienta para avanzar hacia una economía baja en carbono. Existen ya 51 iniciativas de precios sobre el carbono en el ámbito mundial, algunas ya desarrolladas y otras en proceso. 25 de ellas son esquemas de comercio de emisiones ${ }^{2}$ (emissions trading schemes, ETS ${ }^{3}$ ), principalmente desarrollados a nivel subnacional, y 26 son mecanismos basados en la fiscalidad. En 2018 estas iniciativas cubrían 11 gigatoneladas de $\mathrm{CO}_{2 \mathrm{eq}}$ o, lo que es lo mismo, alrededor del $20 \%$ de las emisiones globales de GEI (World Bank Group, 2018).

Conforme a la definición de la OCDE, la fiscalidad medioambiental es el conjunto de impuestos, gravámenes y cánones cuya base imponible es un contaminante o, en general, un producto o servicio que deteriora el entorno o que supone un consumo de recursos naturales. De esta manera, la fiscalidad medioambiental busca integrar en el coste explícito soportado por cada uno de los agentes económicos la totalidad o parte de los costes sociales y medioambientales que ocasionan, es decir, las denominadas externalidades. Así, el recurso a la fiscalidad medioambiental suele venir justificado por el principio «quien contamina paga».

Varios son los impuestos medioambientales que han mostrado su eficacia, como los impuestos sobre el consumo de energías fósiles, que han facilitado la reducción del consumo energético en Europa. No obstante, la fiscalidad medioambiental no se basa únicamente en la fiscalidad energética, dado que en la práctica se aplica a los cuatro grandes problemas medioambientales: el cambio climático, la contaminación, las amenazas sobre la biodiversidad y el consumo excesivo de recursos naturales.

En general, los diseños de política medioambiental más orientados hacia el mercado, frente al resto, favorecen que sean los agentes económicos responsables de las emisiones, en vez de los Gobiernos, quienes decidan cómo gestionar sus emisiones (Averchenkova \& Finnegan, 2018) tal y como sucede con la fiscalidad sobre el carbono.

De todos los mecanismos desarrollados, el Régimen de Comercio de Derechos de Emisión de la Unión Europea (RCDE-UE) ${ }^{4}$ es el que mayor cuota de emisiones de

\footnotetext{
${ }^{2}$ El comercio internacional de permisos de emisión consiste en el intercambio de unidades de $\mathrm{CO}_{2 \mathrm{eq}}$ con el objetivo de lograr una reducción global de las emisiones en las partes involucradas (Larrea Basterra, 2018).

${ }^{3}$ En este documento, los ETS no solo se refieren a sistemas cap-and-trade (en los que se establece un límite al volumen total de emisiones que pueden generarse y, por lo tanto, que pueden comercializarse), sino también a sistemas baseline-and-credit y baseline-and-offset (donde no existe un límite a las unidades que pueden comercializarse).

${ }^{4}$ Se trata de un esquema ETS. La normativa comunitaria ha ido evolucionando a medida que lo ha hecho el RCDE-UE como respuesta a los diferentes retos que se han ido planteando. Para más información ver (Larrea Basterra, 2018).
} 
GEI abarca (World Bank Group, 2018). De hecho, en la actualidad el RCDE-UE es la mayor fuente de ingresos por fijación de precios del carbono debido a su tamaño, seguido por los impuestos al carbono en Francia, Suecia y Japón.

La mayoría de las iniciativas vieron aumentar los precios del carbono en 2018 en comparación con los niveles de 2017. A pesar de estos aumentos, en su mayor parte aún presentan precios por debajo del rango objetivo de cada una de ellas, de 40-80 US\$/tCO 2 para 2020. En particular, aproximadamente la mitad de las emisiones cubiertas por las iniciativas de fijación de precios del carbono tienen un precio inferior a $10 \mathrm{US} \$ / \mathrm{tCO}_{2 \mathrm{eq}}$. A pesar de los recientes aumentos, la mayoría de las trayectorias de precios planificadas no son suficientes y se requiere una mayor escalada en los precios del carbono para alcanzar un impacto significativo sobre las emisiones de $\mathrm{CO}_{2}$ (World Bank Group, 2018).

El objetivo del presente artículo es abordar el tema de la fiscalidad sobre el carbono, centrándose en las experiencias de tres países europeos como son Suecia, que podría denominarse como caso de éxito, Irlanda, que representa el caso de una imposición forzosa por cuestiones de equilibrio presupuestario, y el caso de Francia, el más reciente y que ha puesto al Gobierno francés en alerta ante el descontento de una parte de la población.

Para ello, en primer lugar se presentan datos sobre la historia de su adopción, características de las figuras en cuestión, detalles sobre el destino establecido para los ingresos recaudados y los efectos más relevantes de los impuestos sobre el carbono. Tras la exposición, se recoge un apartado donde se realizan algunas comparaciones de las tres figuras impositivas y se extraen algunas conclusiones.

\section{ALGUNOS DATOS DE LA FISCALIDAD SOBRE EL CARBONO}

En 1992, con ocasión de la Cumbre de la Tierra de Río de Janeiro, la Comisión Europea (la Comisión, en adelante) presentó una propuesta para implantar impuestos nacionales sobre combustibles fósiles, que dependían de su contenido energético y de sus emisiones de GEI. Sin embargo, la propuesta fue abandonada por la oposición de varios Gobiernos, entre ellos el de Francia, con la justificación de proteger la competitividad de su industria pesada.

Tres años después, en mayo de 1995, la Comisión volvió a lanzar una propuesta de características similares, pero más flexible, en cuanto cada Estado miembro podría fijar el tipo impositivo aplicable durante un periodo transitorio que terminaría en el año 2000 (European Commission, Press release database, 1995). De nuevo, la oposición de algunos Gobiernos llevó al rechazo de esta propuesta.

Ante estos dos intentos fallidos parecía evidente que la única forma de adoptar una política de este tipo sería desarrollarla, no en el contexto europeo, sino 
en el estatal. No obstante, la Unión Europea consiguió aprobar y desarrollar el RCDE-UE, que, si bien tenía el mismo objetivo medioambiental (las emisiones de CO2), no necesitaba de un acuerdo unánime a nivel europeo, ya que bastaba con una mayoría cualificada.

Aun así, algunos países decidieron establecer un precio al carbono en su ámbito nacional, bien mediante impuestos al carbono propiamente dichos (Dinamarca, Holanda, Noruega, Suecia, Irlanda e Italia) o mediante un incremento de los impuestos energéticos (Austria y Alemania).

Si bien son numerosos los países que han implementado una fiscalidad sobre el carbono de manera sistemática, pueden distinguirse dos grandes olas en su desarrollo. En primer lugar, se encuentra la que data de los años noventa en Finlandia (1990) y los países escandinavos (Noruega y Suecia en 1991 y Dinamarca en 1992). La segunda, que se inició alrededor de 2008, no tiene un enfoque geográfico tan marcado y pueden destacarse los casos de Suiza (2008) y de Irlanda (2010) (Ministère de la Transitions Écologique et Solidaire, 2017), (Garrido, 2017). Más reciente es el caso de Francia, que data de 2014.

Tabla 1. Ejemplos de impuestos sobre el carbono en el mundo

\begin{tabular}{|c|c|c|c|c|c|c|c|c|c|c|}
\hline & 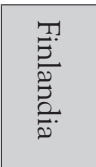 & 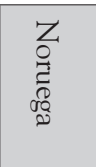 & $\begin{array}{l}\infty \\
\stackrel{0}{D} \\
\frac{2}{2} .\end{array}$ & 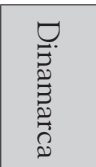 & 品. & 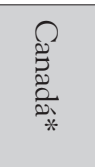 & 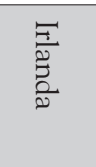 & 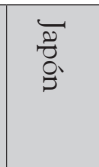 & $\begin{array}{l}\frac{3}{2} \\
\frac{\pi}{\alpha} \\
\frac{3}{6}\end{array}$ & 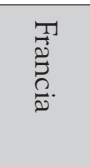 \\
\hline $\begin{array}{l}\text { Año de puesta en } \\
\text { funcionamiento }\end{array}$ & 1990 & 1991 & 1991 & 1992 & 2008 & 2008 & 2010 & 2012 & 2012 & 2014 \\
\hline $\begin{array}{l}\text { Tipo impositivo } \\
\left(€ / \mathrm{tCO}_{2 \mathrm{eq}}\right)\end{array}$ & $\begin{array}{l}35-60 \\
(2015)\end{array}$ & $\begin{array}{c}45 \\
(2015)\end{array}$ & $\begin{array}{c}120 \\
(2015)\end{array}$ & $\begin{array}{c}22,8 \\
(2015)\end{array}$ & $\begin{array}{c}76 \\
(2016)\end{array}$ & $\begin{array}{c}20 \\
(2015)\end{array}$ & $\begin{array}{c}20 \\
(2015)\end{array}$ & $\begin{array}{c}2,4 \\
(2015)\end{array}$ & $\begin{array}{c}0,9 \\
(2015)\end{array}$ & $\begin{array}{c}30,5 \\
(2017)\end{array}$ \\
\hline
\end{tabular}

Nota*: Canadá: Columbia Británica y Alberta.

Fuente: (Service de l'économie, de l'évaluation et de l'intégration du développement durable, 2017).

Conviene señalar, antes de continuar, que las comparaciones sobre el impacto de los impuestos sobre el carbono deben realizarse con precaución. El tamaño, la economía y la población de cada país plantean diferencias en los niveles de recaudación, más allá del propio componente de carbono.

Así, en primer lugar, conviene relativizar los datos absolutos, como se recoge en el siguiente gráfico. En él se puede observar que Dinamarca es el país donde los impuestos medioambientales han tenido y tienen un mayor peso respecto al PIB. Irlanda presentaba en 1995 un mayor nivel de recaudación por nivel de PIB que 
Francia y Suecia. Sin embargo, tenía una menor recaudación en términos absolutos. Dos décadas después, es Francia el país de los tres que mayor porcentaje de impuestos medioambientales sobre PIB presenta, seguida de Suecia e Irlanda. En los tres casos la recaudación total por este tipo de impuestos aumentó.

\section{Gráfico 1. Fiscalidad medioambiental en varios países europeos y\% sobre el PIB}
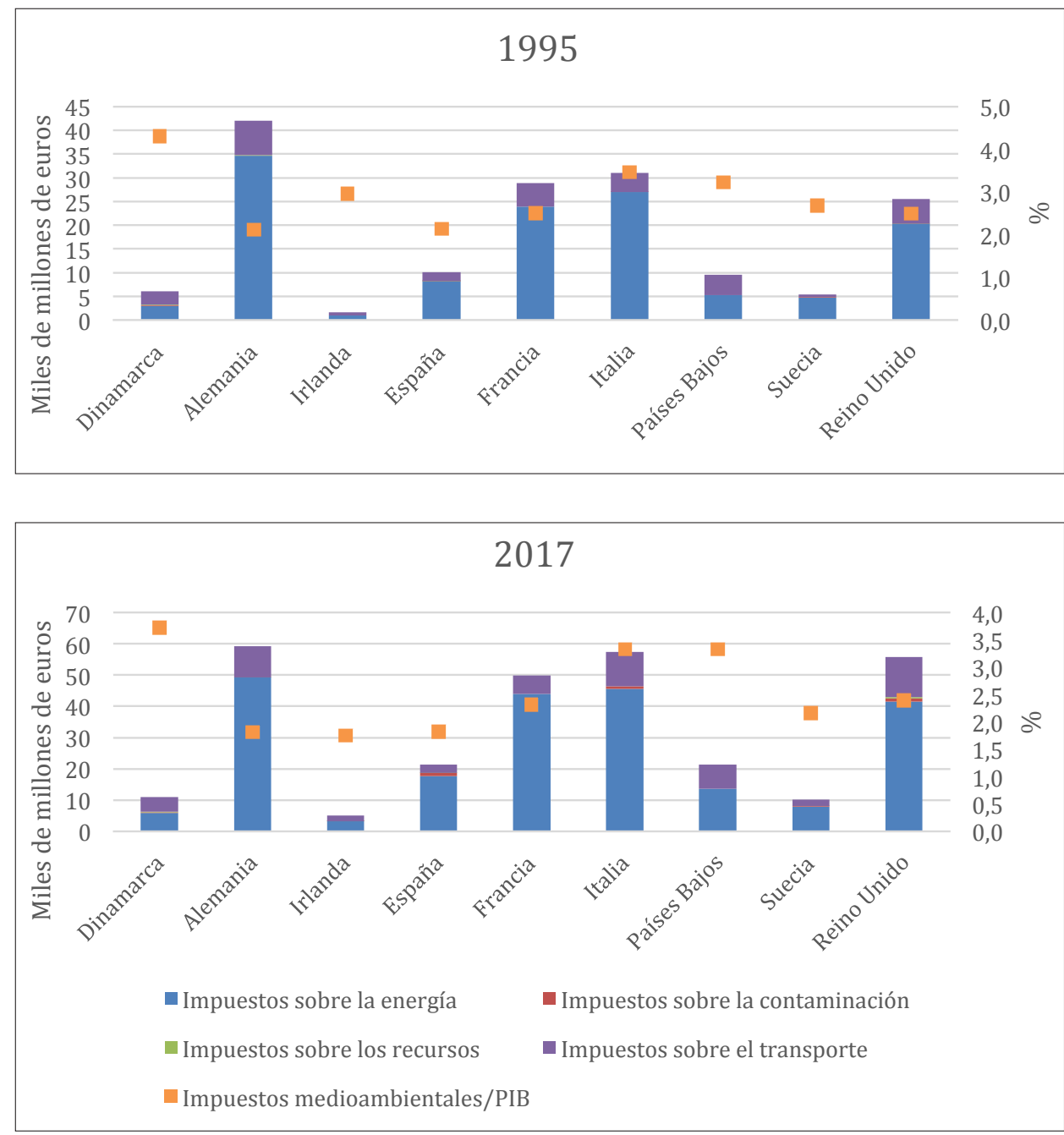

Fuente: elaboración propia a partir de Eurostat. 
También puede compararse la relación entre la recaudación fiscal por los impuestos medioambientales y la población, tal y como se muestra en la siguiente tabla. En todos los casos se ha producido un aumento más o menos progresivo de la ratio entre 1995 y 2017.

Tabla 2. Recaudación de impuestos medioambientales por habitante $(€ /$ habitante)

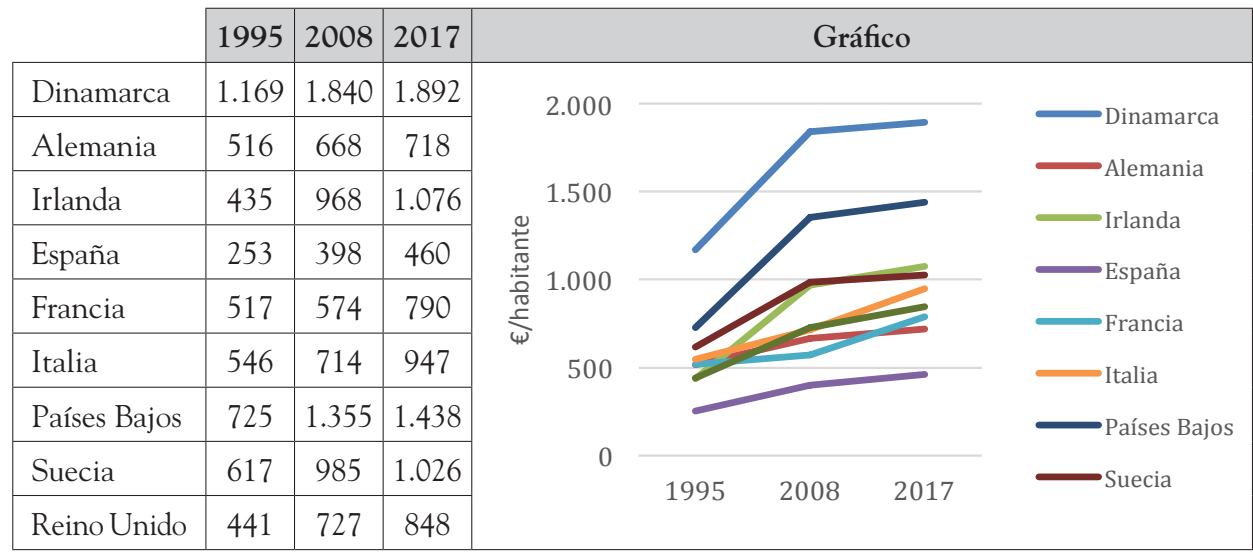

Fuente: elaboración propia a partir de Eurostat.

El siguiente gráfico pone en relación la recaudación en términos de impuestos medioambientales con las emisiones de gases de efecto invernadero, lo que podría interpretarse como un "coste ficticio" del $\mathrm{CO}_{2 \text { eq }}$. No obstante, debe recordarse que los impuestos medioambientales también incluyen otros conceptos como las emisiones de contaminantes.

Gráfico 2. Recaudación de impuestos ambientales por tonelada de $\mathrm{CO}_{2 \mathrm{eq}}$ emitida en Francia y por país

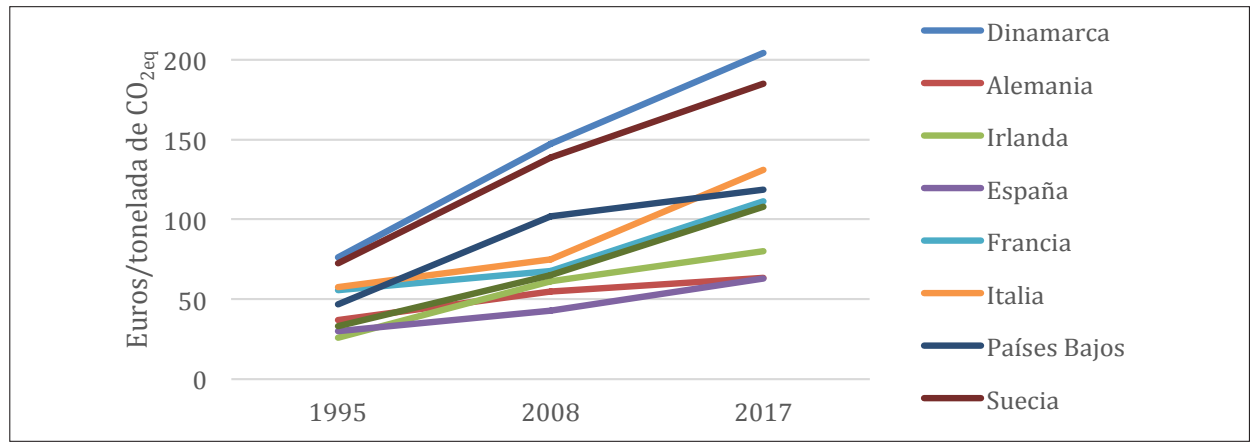

Fuente: elaboración propia a partir de Eurostat y EEA.

icade. Revista cuatrimestral de las Facultades de Derecho y Ciencias Económicas y Empresariales, $n^{\circ} 108$ septiembre-diciembre 2019, ISSN: 2341-0841 


\section{LA FISCALIDAD SOBRE EL CARBONO EN SUECIA}

En la actualidad, la fiscalidad medioambiental en Suecia se estructura en torno a cuatro grandes herramientas: (1) los impuestos sobre la energía, (2) el impuesto sobre el $\mathrm{CO}_{2}$, (3) un conjunto de diversos impuestos y tasas medioambientales y (4) impuestos relacionados con el uso de vehículos.

El impuesto general sobre la energía (introducido en los años 50) se aplica a todos los combustibles fósiles (petróleo y derivados, gas natural y carbón) que se utilizan para combustión, calefacción y transporte, excepto a la mayor parte de los biocombustibles 5 .

Además, todos los consumidores deben pagar un impuesto por su consumo de electricidad. Los consumidores industriales y agrícolas pagan un tipo impositivo por la electricidad más elevado que los consumidores domésticos y comerciales (OECD, 2018).

El impuesto sobre el carbono se aplica a los combustibles que emiten $\mathrm{CO}_{2}$ (excepto a los biocombustibles y a la turba) en todos los sectores no sujetos al RCDE-UE. Hasta enero de 2018 existían exenciones y tipos especiales para la industria intensiva en energía y para el diésel que se utilizaba como combustible en la industria agrícola, el sector pesquero, etc.

Entre los demás impuestos medioambientales se incluyen un impuesto sobre las emisiones de productos con azufre, que se aplica al petróleo y sus derivados (incluyendo la gasolina y el diésel), el carbón y la turba; otros impuestos (sobre pesticidas, desechos en vertederos y extracciones de grava) y algunos impuestos relacionados con la adquisición y el uso del vehículo, la circulación o el ligado a los atascos de tráfico (Trängselskatt).

Los impuestos sobre la energía representaron en 2016 aproximadamente la mitad de los ingresos fiscales medioambientales, como puede verse en la siguiente tabla, mientras que el impuesto sobre el $\mathrm{CO}_{2}$ supuso aproximadamente un $27 \%$.

En conjunto, los impuestos energéticos y medioambientales alcanzaron aproximadamente el 5\% de la recaudación fiscal total en Suecia en 2015.

\footnotetext{
${ }^{5}$ Desde enero de 2013 los biocombustibles que se utilizan en el transporte están exentos del impuesto sobre el carbono y, en función del tipo de biocombustible, de toda o la mayor parte del impuesto sobre la energía.
} 
La fiscalidad sobre el carbono. Una aproximación a los casos de Suecia, Irlanda y Francia

Tabla 3. Desglose de los ingresos fiscales medioambientales en Suecia (2016)

\begin{tabular}{|c|c|c|}
\cline { 2 - 3 } \multicolumn{1}{c|}{} & $\begin{array}{c}\text { Ingresos (2016) } \\
\text { (miles de millones de euros) }\end{array}$ & $\begin{array}{c}\text { Porcentaje } \\
\text { respecto al total }\end{array}$ \\
\hline A) Impuesto sobre la energía & 4,80 & $52,63 \%$ \\
\hline Electricidad & 2,29 & $25,11 \%$ \\
\hline Gasolina & 1,26 & $13,82 \%$ \\
\hline Otros combustibles fósiles & 1,25 & $13,71 \%$ \\
\hline B) Impuesto sobre el CO & 2,44 & $26,75 \%$ \\
\hline Gasolina & 0,87 & $9,54 \%$ \\
\hline Otros combustibles fósiles & 1,57 & $17,21 \%$ \\
\hline C) Otros impuestos medioambientales & 0,041 & $0,45 \%$ \\
\hline $\begin{array}{l}\text { Impuesto sobre compuestos } \\
\text { sulfurados }\end{array}$ & 0,001 & $0,01 \%$ \\
\hline Impuesto sobre pesticidas & 0,01 & $0,11 \%$ \\
\hline Impuesto sobre vertidos & 0,01 & $0,11 \%$ \\
\hline Impuesto sobre grava y gravillas & 0,02 & $0,22 \%$ \\
\hline D) Impuestos relacionados con vehículos & 1,84 & $20,18 \%$ \\
\hline Impuesto sobre los vehículos & 1,50 & $16,45 \%$ \\
\hline a motor & 0,08 & $0,88 \%$ \\
\hline Cargos por uso de carreteras & 0,26 & $2,85 \%$ \\
\hline Impuesto sobre atascos/congestión & 9,12 & $100,00 \%$ \\
\hline TOTAL (A+B+C+D) & & \\
\hline
\end{tabular}

Fuente: elaboración propia a partir de Akerfeldt (2016). 


\section{CRONOLOGÍA DE LA FISCALIDAD SOBRE EL CARBONO EN SUECIA}

En los años noventa se implementó en Suecia una "reforma fiscal verde" de calado, en un contexto de elevado déficit fiscal y crisis financiera (Akerfeldt, 2016; Bureau, 2013). A la vez, se recortaron los impuestos sobre el trabajo, los tipos marginales del impuesto sobre la renta, el impuesto sobre los beneficios empresariales y el impuesto sobre la energía, se aplicó el IVA sobre los productos energéticos y se crearon impuestos sobre el carbono (con un tipo reducido para la industria) y sobre las emisiones de dióxido de azufre $\left(\mathrm{SO}_{2}\right)$.

El impuesto sobre el carbono se aplicó inicialmente como un impuesto sobre el consumo de energía, con reducciones para la industria intensiva en energía y la horticultura, gravando todos los combustibles que emitían $\mathrm{CO}_{2}\left(250 \mathrm{kr} / \mathrm{tCO}_{2}\right.$, equivalentes a unos $27 € / \mathrm{tCO}_{2}$ ), salvo a la generación eléctrica.

En 1993 se introdujo un esquema con dos tipos impositivos: el tipo general y un tipo especial para la industria. Pese a todo, se aprobó una normativa por la que la industria intensiva en energía todavía podía alcanzar reducciones adicionales en el tipo impositivo ${ }^{6}$.

En 2000 se implementó una segunda ronda de reformas fiscales, incrementándose gradualmente el tipo general del impuesto sobre el carbono casi un 250\%, partiendo de $370 \mathrm{kr} / \mathrm{tCO}_{2}$ hasta $910 \mathrm{kr} / \mathrm{tCO}_{2}$ en 2005. El impuesto sobre la energía se modificó a su vez para no alterar el coste relativo entre electricidad y combustibles fósiles (Scharin \& Wallström, 2018).

En 2008 volvió a incrementarse el tipo del impuesto sobre el carbono y en 2011 quedaron exentas de este impuesto las empresas sujetas al RCDE-UE. Apenas un año después, tras la aprobación de la Ley Climática de 2009, se aprobaron subidas en el tipo impositivo para la industria que se implementaron en 2010, 2011, 2013 y 2015, hasta que a partir del 1 de enero de 2018 se igualaron los tipos (general y de la industria), fijándose el nivel común en $1.180 \mathrm{kr} / \mathrm{tCO}_{2}$ (alrededor de 120 euros). A partir de enero de 2013 se eximió a la cogeneración del impuesto sobre el carbono, aunque a cambio se le aplicó el impuesto general sobre la energía.

En los últimos años, especialmente a partir de la aprobación del Marco de Política Climática, se ha reforzado el papel de la fiscalidad medioambiental como instrumento para modificar el comportamiento de los consumidores y para alcanzar los objetivos climáticos.

La siguiente figura muestra un cronograma con la evolución del impuesto sobre el carbono en Suecia desde su introducción en 1991.

\footnotetext{
${ }^{6}$ Por ejemplo, la industria metalúrgica (hierro y acero) estaba exenta del impuesto sobre las emisiones de dióxido de azufre y el impuesto sobre el carbono se limitaba a un máximo del 1,7\% del valor de la producción (posteriormente, el 1,2\% y el 0,8\%, dependiendo del subsector) (Lin \& Li, 2011).
} 
LA fiscalidad sobre el carbono. Una aproximación a los casos de Suecia, Irlanda y Francia

Figura 1. Evolución del impuesto sobre el carbono en Suecia

\begin{tabular}{|c|c|}
\hline 1991 & $\begin{array}{l}\text { Introducción del impuesto sobre el } \mathrm{CO}_{2} \text {, con tipos impositivos menores para la } \\
\text { industria intensiva en energía y la horticultura. }\end{array}$ \\
\hline 1993 & $\begin{array}{l}\text { Los tipos impositivos desaparecen y se define un tipo general más bajo para toda } \\
\text { la industria. }\end{array}$ \\
\hline 1995 & Suecia entra a formar parte de la Unión Europea. \\
\hline 2000 & Reforma fiscal verde. \\
\hline 2005 & $\begin{array}{l}\text { Comienza a funcionar el régimen de comercio de derechos de emisión de la UE } \\
\text { (RCDE-UE). }\end{array}$ \\
\hline 2008 & $\begin{array}{l}\text { El Gobierno aumenta el impuesto sobre el } \mathrm{CO}_{2} \text { en } 60 \mathrm{SEK} / \text { tonelada, hasta } 1.010 \\
\text { SEK/tonelada. }\end{array}$ \\
\hline 2009 & $\begin{array}{l}\text { La Ley sobre el clima }(2009 / 10: 41) \text { propone un precio uniforme para el } \mathrm{CO}_{2} \text {, elimi- } \\
\text { nando los tipos impositivos especiales. }\end{array}$ \\
\hline 2011 & $\begin{array}{l}\text { Se exime a la industria sujeta al RCDE-UE del impuesto sobre el carbono. Aumenta } \\
\text { el tipo impositivo para la industria en sectores difusos. }\end{array}$ \\
\hline 2015 & $\begin{array}{l}\text { Vuelve a aumentar el tipo impositivo sobre el carbono para la industria no sujeta } \\
\text { al RCDE-UE. }\end{array}$ \\
\hline 2017 & Nuevos objetivos climáticos. \\
\hline 2018 & $\begin{array}{l}\text { Se elimina la reducción en el tipo impositivo para la industria no sujeta al RCDE-UE } \\
\text { (todos los sectores tienen ahora el mismo tipo impositivo). }\end{array}$ \\
\hline
\end{tabular}

Fuente: elaboración propia a partir de Scharin \& Wallström (2018).

\section{EL IMPUESTO SOBRE EL CARBONO}

El impuesto sobre el carbono se aplica a todos los combustibles utilizados para combustión y calefacción/calor que emiten $\mathrm{CO}_{2}$, excepto en gran parte de los biocombustibles y de la biomasa (utilizada, por ejemplo, para los sistemas de calefacción colectiva en los núcleos urbanos).

Como se ha señalado, el impuesto no se aplica a las actividades sujetas al RCDE-UE y, por ello, al consumo de combustibles fósiles para la generación de electricidad ni al consumo de energía para la realización de estas actividades. En total, el $90 \%$ de las emisiones de $\mathrm{CO}_{2}$ en Suecia están sujetas en la actualidad a la aplicación de un precio del carbono, bien a través del Régimen de Comercio de Derechos de Emisión, bien a través del impuesto sobre ${\mathrm{el} \mathrm{CO}_{2} \text { ? }}^{7}$

\footnotetext{
${ }^{7}$ Akerfeldt (2016).
} 
Tabla 4. Tipo impositivo sobre el $\mathrm{CO}_{2}$ en 2018

\begin{tabular}{|l|l|l|l|}
\cline { 2 - 4 } \multicolumn{1}{c|}{} & \multicolumn{1}{c|}{ Unidad } & \multicolumn{1}{c|}{ Tasa $(\mathrm{kr})$} & \multicolumn{1}{c|}{ Tasa $(€)$} \\
\hline Gasolina & Litro & 2,66 & 0,266 \\
\hline Combustible para aviación & Litro & 2,66 & 0,266 \\
\hline Diésel & Litro & 3,29 & 0,329 \\
\hline Fuelóleo para calefacción & $\mathrm{m}^{3}$ & 3.292 & 329,2 \\
\hline Gasóleo & Tonelada & 3.463 & 346,3 \\
\hline Carbón & Tonelada & 2.865 & 286,5 \\
\hline Gas natural & $1.000 \mathrm{~m}^{3}$ & 2.465 & 246,5 \\
\hline
\end{tabular}

Nota: en la conversión a euro $(€)$ se aplica un tipo de cambio igual a 1 corona sueca $(\mathrm{kr})=0,1$ euro.

Fuente: elaboración propia a partir de Scharin \& Wallström (2018).

El impuesto aplicable al consumo de cada tipo de energía se calcula teniendo en cuenta las emisiones medias de $\mathrm{CO}_{2}$ de los distintos combustibles, por lo que no se miden las emisiones específicas de puntos concretos o instalaciones de consumo, y se expresan en unidades de volumen o peso estándares (litros, kilos y metros cúbicos).

Tabla 5. Cálculo del impuesto sobre el $\mathrm{CO}_{2}$ en Suecia

\begin{tabular}{|c|c|c|c|c|c|c|}
\hline Combustible & Unidad & $\begin{array}{l}\text { Contenido } \\
\text { energético } \\
\mathrm{kWh} / \mathrm{unidad} \\
\text { (1) }\end{array}$ & $\begin{array}{l}\text { Emisiones } \\
\text { de } \mathrm{CO}_{2} \\
\mathrm{~kg} / \mathrm{MJ}(2)\end{array}$ & $\begin{array}{l}\text { Emisiones } \\
\text { de } \mathrm{CO}_{2} \\
\mathrm{~kg} / \mathrm{unidad} \\
\text { (3) }\end{array}$ & $\begin{array}{c}\text { Impuesto } \\
\mathrm{CO}_{2} \mathrm{SEK} / \\
\text { unidad } \\
1991(4)\end{array}$ & $\begin{array}{c}\text { Impuesto } \\
\mathrm{CO}_{2} \text { SEK/ } \\
\text { unidad } \\
2010(5)\end{array}$ \\
\hline Gasóleo & $\mathrm{m}^{3}$ & 9.900 & 0,077 & 2.744 & 714 & 2.998 \\
\hline $\begin{array}{l}\text { Fuelóleo } \\
\text { pesado }\end{array}$ & $\mathrm{m}^{3}$ & 10.700 & 0,077 & 2.966 & 714 & 2.998 \\
\hline Carbón & ton & 7.500 & 0,092 & 2.484 & 621 & 2.608 \\
\hline Gas natural & $1.000 \mathrm{~m}^{3}$ & 10.800 & 0,055 & 2.138 & 535 & 2.245 \\
\hline GLP & ton & 12.790 & 0,065 & 2.993 & 748 & 3.143 \\
\hline Gasolina & $\mathrm{m}^{3}$ & 8.720 & 0,074 & 2.323 & 581 & 2.439 \\
\hline $\begin{array}{l}\text { Madera y } \\
\text { residuos } \\
\text { forestales }\end{array}$ & ton & 3.530 & 0 & 0 & 0 & 0 \\
\hline
\end{tabular}

Fuente: elaboración propia a partir de Hammar \& Akerfeldt (2011). 
Tal y como se ha señalado, el tipo impositivo sobre el $\mathrm{CO}_{2}$ fue aumentando progresivamente desde los $27 € / \mathrm{tCO}_{2}\left(250 \mathrm{kr} / \mathrm{tCO}_{2}\right)$ para los consumidores industriales y los $8 € / \mathrm{tCO}_{2}$ en los sectores no sujetos al RCDE-UE que se aplicaron al inicio del esquema. En 2004, el tipo general se situaba ya en $95 € / \mathrm{tCO}_{2}$, mientras que el de las instalaciones industriales en sectores difusos se situaba en $20 € / \mathrm{tCO}_{2}$.

A partir de 2010, el tipo impositivo aplicable a las instalaciones industriales comenzó a incrementarse en mayor medida que el tipo impositivo general. Así, el 1 de enero de 2018 se igualaron ambos tipos, situándose el tipo impositivo del $\mathrm{CO}_{2}$ en $120 € / \mathrm{tCO}_{2}$ para todos los consumos sujetos al impuesto.

\section{Gráfico 3. Evolución del impuesto sobre el carbono en Suecia $\left(€ / \mathrm{tCO}_{2}\right)$}

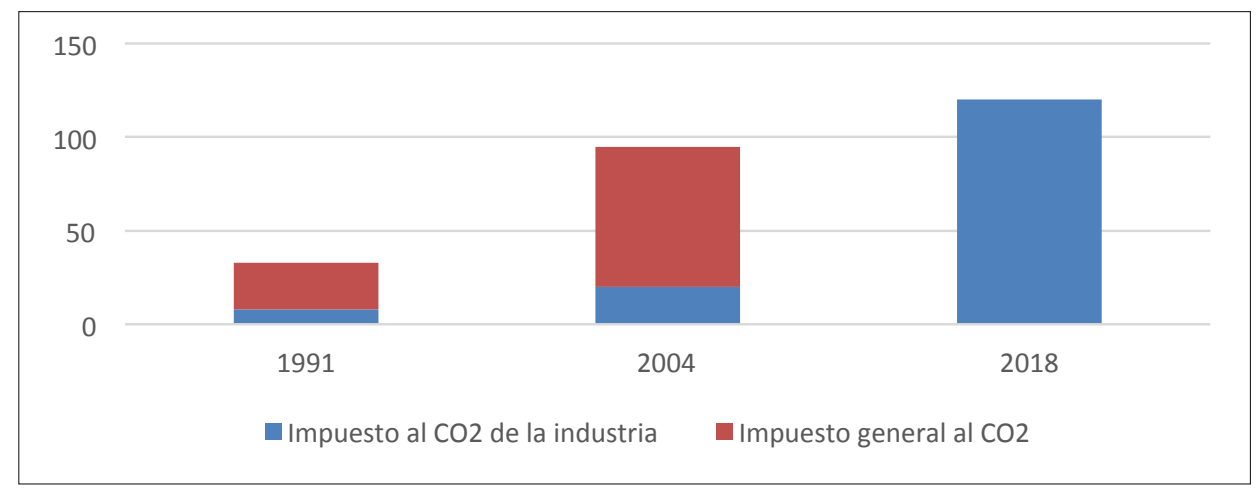

Fuente: elaboración propia a partir de Government Offices of Sweden (2018), Akerfeldt (2016) y Ackva \& Hoppe (2018).

\section{DESTINO DE LOS INGRESOS FISCALES Y ASPECTOS SOCIALES Y DISTRIBUTIVOS}

En origen, la estrategia sueca de utilización de los ingresos derivados de la fiscalidad medioambiental ha buscado generar un doble dividendo, al menos parcialmente, "reciclando" los impuestos y devolviéndoselos a empresas y hogares mediante la rebaja de los impuestos sobre el trabajo y la renta y algunas otras transferencias.

En el modelo sueco, los ingresos derivados del impuesto sobre el carbono se integran en los presupuestos del Estado y, a partir de ahí, se distribuyen para la financiación de diversos programas e iniciativas, entre ellas medioambientales relativas a energías renovables, a eficiencia energética u orientadas a facilitar la transición energética hacia una economía baja en carbono. También se emplean con fines redistributivos, mediante esquemas de apoyo a los hogares vulnerables que se financian en su totalidad a través de los presupuestos del Estado. 
Desde la aprobación del Marco de Política Climática en 2017 han aumentado las partidas de los presupuestos del Estado orientadas a alcanzar objetivos medioambientales. Así, en los Presupuestos de 2017 se aprobaron inversiones por valor de 1.400 millones de euros en el periodo 2017-2020 relacionadas con medidas para mitigar el cambio climático en el ámbito local, el transporte limpio (inversiones en las ciudades) y las energías renovables (exenciones fiscales para las instalaciones fotovoltaicas en el sector residencial) y una partida de 33 millones de euros/año en el periodo 2018-2040 para comprar derechos de emisión de $\mathrm{CO}_{2}$ y cancelar las obligaciones asociadas (Akerfeldt, 2016).

\section{EFECTOS DE LA INTRODUCCIÓN DEL IMPUESTO SOBRE EL CARBONO}

La profunda reforma fiscal energética y medioambiental en Suecia, iniciada a principios de los años 90, se cita a menudo en la literatura académica como un ejemplo de reforma exitosa, que ha contribuido a avanzar en la transición energética hacia una economía con menores emisiones de gases de efecto invernadero sin comprometer la competitividad de la economía sueca (Perthuis \& Fauré, 2018).

Aunque resulta complicado distinguir los efectos de la introducción del impuesto sobre el carbono del resto de políticas energéticas, medioambientales y fiscales, se observa una tendencia a la baja en las emisiones totales de $\mathrm{CO}_{2}$ desde mediados de la década de los noventa y un claro desacoplamiento de las emisiones contaminantes y del crecimiento económico.

Tomando como referencia 1990, los datos oficiales del Gobierno sueco muestran un incremento del PIB entre 1990-2016 del 75\%, frente a una caída en las emisiones de $\mathrm{CO}_{2}$ del 26\%.

Tabla 6. Evolución de las emisiones de GEI por sector (con las políticas actuales)

\begin{tabular}{|l|c|c|c|c|c|c|c|c|}
\hline & $\%$ & 2015 & 2020 & 2025 & 2030 & 2035 & $1990-2020$ & $1990-2030$ \\
\hline $\begin{array}{l}\text { Energía (excluido el } \\
\text { transporte) }\end{array}$ & 33,8 & 20,8 & 20,7 & 20,2 & 19,3 & 18,4 & $-39 \%$ & $-43 \%$ \\
\hline Transporte & 19,3 & 18,2 & 15,4 & 14,3 & 13,6 & 13,1 & $-20 \%$ & $-30 \%$ \\
\hline $\begin{array}{l}\text { Procesos industriales y } \\
\text { usos de productos }\end{array}$ & 7,2 & 6,4 & 6,3 & 6,2 & 6,1 & 6,0 & $-12 \%$ & $-15 \%$ \\
\hline Agricultura & 7,6 & 6,9 & 6,4 & 6,1 & 5,9 & 5,4 & $-17 \%$ & $-23 \%$ \\
\hline Residuos & 3,7 & 1,4 & 1,1 & 0,9 & 0,7 & 0,7 & $-72 \%$ & $-81 \%$ \\
\hline LULUCF* & $-16,7$ & $-50,5$ & $-43,3$ & $-44,3$ & $-42,2$ & $-40,5$ & $18 \%$ & $15 \%$ \\
\hline
\end{tabular}

Nota: * L Land Use, Land-Use Change and Forestry.

Fuente: elaboración propia a partir de Swedish Energy Agency (2018). 
Probablemente los efectos más directos del impuesto sobre el carbono puedan observarse en el sector de la edificación (en el uso de energía para calefacción y agua caliente) y en el transporte. La evolución de las emisiones en el sector de la edificación muestra un acusado descenso en las emisiones de los edificios residenciales entre 1990 y 2015 (Scharin \& Wallström, 2018). Las principales razones fueron la sustitución del gasóleo y de otras fuentes de energía contaminantes por otras fuentes de calefacción (district heating o redes de calor, bombas de calor, radiadores eléctricos, etc.) y las mejoras en la eficiencia energética de los hogares (Scharin \& Wallström, 2018).

Andersson (2017), utilizando un modelo econométrico, estimó el efecto del impuesto sobre el carbono sobre las emisiones del sector del transporte en Suecia entre 1990 y 2005. En ese periodo el impuesto sobre el carbono contribuyó a reducir las emisiones de $\mathrm{CO}_{2}$, respecto de la referencia (1990), en un 6,3\% anual (como promedio). En 2005, el modelo estadístico atribuía al impuesto sobre el carbono una reducción del 9,4\% de las emisiones de $\mathrm{CO}_{2}$ respecto de 2004, tres cuartas partes de la reducción total conseguida dicho año. El resto de la reducción de las emisiones se atribuyó al incremento del IVA aplicable a los combustibles.

En el caso de la industria, se observa una reducción del 10\% en las emisiones de $\mathrm{CO}_{2}$ relacionadas con el consumo de energía entre 1990 y 2014 y una caída en la intensidad de $\mathrm{CO}_{2}$ de la energía utilizada ${ }^{8}$, pero el impuesto sobre el carbono probablemente desempeñó un papel secundario en dichas tendencias debido a los cambios en infraestructuras, equipamientos y procesos (Ackva \& Hoppe, 2018).

En lo que se refiere a las variables macroeconómicas, la evidencia empírica disponible, si bien escasa, sugiere que el impacto de la reforma fiscal medioambiental en Suecia (incluyendo el impuesto sobre el carbono) fue positivo en términos del PIB, aunque el efecto sobre la inflación fue relativamente elevado, en comparación con otros países, lo que puede deberse a la forma de "reciclar" los ingresos medioambientales (reducciones en el impuesto sobre la renta) (Skou, 2010).

\section{LA FISCALIDAD SOBRE EL CARBONO EN IRLANDA}

Irlanda ha sido uno de los Estados miembros pioneros en la implementación de un impuesto sobre las emisiones de $\mathrm{CO}_{2}$ sobre los llamados sectores difusos, es decir, los sectores no sujetos al RCDE-UE, especialmente el transporte y los sectores residencial y terciario, por el uso de energía para calefacción (Galindo, Beltrán, Ferrer Carbonell \& Alatorre, 2017).

\footnotetext{
${ }^{8}$ Pardo Martínez, C.I. \& Silveira, S. (2013) estiman que el desacoplamiento entre la producción industrial y las emisiones de $\mathrm{CO}_{2}$ en Suecia entre 1993 y 2008 se debió a cambios estructurales hacia industrias más ligeras y a la menor intensidad energética e intensidad de carbono.
}

icade. Revista cuatrimestral de las Facultades de Derecho y Ciencias Económicas y Empresariales, $n^{2} 108$ septiembre-diciembre 2019, ISSN: 2341-0841 
De acuerdo con la Agencia Estadística Estatal irlandesa (Central Statistics Office, $\mathrm{CSO}$ ), el conjunto de impuestos medioambientales en Irlanda supuso en $2017 \mathrm{el}$ $7,8 \%$ de la recaudación total. Este porcentaje ha decrecido de forma continuada en los últimos años (en 2013 se situaba en el 8,9\%), aunque se mantiene por encima de la media de la UE-28 del 6,3\%9 y ello, a pesar de que el volumen total de la recaudación no ha cesado de aumentar año tras año.

Tabla 7. Evolución de la recaudación por los impuestos medioambientales en Irlanda (millones de euros)

\begin{tabular}{|l|c|c|c|c|c|}
\cline { 2 - 6 } \multicolumn{1}{c|}{} & 2013 & 2014 & 2015 & 2016 & 2017 \\
\hline Energía & 2.721 & 2.811 & 3.026 & 3.107 & 3.196 \\
\hline Transporte & 1.662 & 1.783 & 1.873 & 1.910 & 1.915 \\
\hline Contaminación y recursos & 59 & 48 & 47 & 58 & 51 \\
\hline Total & 4.442 & 4.642 & 4.947 & 5.074 & 5.162 \\
\hline \% de la recaudación total & $8,9 \%$ & $8,5 \%$ & $8,3 \%$ & $8,1 \%$ & $7,8 \%$ \\
\hline
\end{tabular}

Fuente: (Central Statistics Office (CSO), 2018).

Los impuestos sobre la energía, entre los que se incluye el impuesto al carbono, supusieron dicho año el $62 \%$ de los ingresos totales derivados de los impuestos medioambientales. Por su parte, el impuesto sobre el carbono supuso una recaudación de 429 millones de euros en 2017, el 0,7\% de la recaudación fiscal total del país. En los últimos años, la recaudación de este impuesto se ha estabilizado en torno al 0,7\% de la recaudación fiscal total.

\section{CRONOLOGÍA DE LA FISCALIDAD SOBRE EL CARBONO EN IRLANDA}

En el momento de su aprobación, el impuesto sobre el carbono no se justificó por una necesidad medioambiental, sino, principalmente, por su probable contribución a la corrección del déficit público y a la delicada situación financiera de la economía irlandesa, cuya deuda pública había aumentado desde el 12,1\% en 2006 hasta el 74,7\% en 2010 (Convery, 2013).

Las negociaciones con la Troika (Banco Central Europeo, Fondo Monetario Internacional y Comisión Europea) dieron lugar a un acuerdo por el cual Irlanda recibiría apoyo financiero a cambio de la implementación de determinadas medidas

\footnotetext{
${ }^{9}$ (Comisión Europea, 2018b).
} 
para incrementar los ingresos fiscales y reducir el gasto público. Una de estas medidas fue la introducción de un impuesto al carbono (Convery, 2014).

Otros factores que contribuyeron a la aprobación del impuesto sobre el carbono en Irlanda fueron el liderazgo del Partido Verde, una percepción social generalmente favorable a las reformas propuestas para fomentar la "economía verde" ${ }^{10}$, el apoyo del mundo académico y de la investigación, y la posibilidad de establecer exenciones para sectores especialmente afectados y opuestos a la introducción del impuesto, como el agrícola o el de las grandes instalaciones industriales (Convery, 2013; Convery, 2014).

Así, en 2009, el Gobierno de Irlanda aprobó, a propuesta de la Comisión sobre Fiscalidad (Commission on Taxation) ${ }^{11}$, la introducción de un impuesto sobre las emisiones de $\mathrm{CO}_{2}$ derivadas del consumo de productos energéticos, líquidos y sólidos ${ }^{12}$, en algunos de los sectores económicos no sujetos al RCDE-UE y su inclusión en los Presupuestos de $2010^{13}$.

La implementación de este impuesto fue gradual. En 2009, se aplicó inicialmente a los combustibles para el transporte (gasolina, diésel). En 2010, se amplió a otros combustibles líquidos o gaseosos (queroseno, GLP, gas natural, fuelóleo, etc.) y, en 2013 y 2014, se extendió al resto de combustibles sólidos, como el carbón y la turba.

En los primeros años tras su entrada en vigor, el impuesto sobre el carbono contribuyó de forma significativa a cumplir con los requerimientos de la Troika. Así, entre 2010 y 2012 los ingresos acumulados de 919 millones de euros supusieron un incremento del $12,4 \%$ de los ingresos fiscales totales acumulados que requería el plan de financiación (Tol, 2008).

\section{EL IMPUESTO SOBRE LAS EMISIONES DE $\mathrm{CO}_{2}$}

En principio, el impuesto sobre el carbono era aplicable a los consumos de combustibles fósiles en algunos sectores, como el residencial, el terciario, el transporte y la industria.

${ }^{10}$ Pese al apoyo social general a las políticas de protección del medioambiente y de sostenibilidad energética, la sociedad irlandesa no es, en la actualidad, una de las más concienciadas o activas en la Unión Europea (Comisión Europea, 2018c).

11 (Commission on Taxation, 2009).

${ }^{12}$ Incluyendo la gasolina, el diésel, el fuelóleo y otros derivados del petróleo, el carbón, el gas natural y la turba.

${ }^{13}$ La Comisión sobre Fiscalidad estableció una serie de requisitos que debía cumplir el nuevo impuesto. Este debería estar basado en medidas estandarizadas (i.e., de acuerdo con los estándares internacionales) del contenido de $\mathrm{CO}_{2}$ de cada combustible. El tipo impositivo debería acercarse, cada año, al precio del $\mathrm{CO}_{2}$ en el RCDE-UE, fijándose un suelo a dicho precio. El crecimiento gradual del tipo impositivo debería depender del nivel del precio. El impuesto debería recaudarse en los puntos de venta a consumidores y estar ligado al esquema fiscal vigente para los productos petrolíferos en la medida de lo posible. Además, debería ser un impuesto visible para los consumidores, para evitar que fuera percibido como un impuesto más. En general, no deberían fijarse tipos impositivos preferenciales (Commission on Taxation, 2009). 
Quedaban excluidos los sectores sujetos al RCDE-UE, como la generación de energía eléctrica y las grandes instalaciones industriales, para evitar una doble imposición, así como la mayor parte de las emisiones de GEI del sector agrícola (principalmente, metano y óxido de nitrógeno) y del sector de los residuos. La razón esgrimida por el Gobierno fue la dificultad de medir, monitorizar y verificar las emisiones en estos sectores ${ }^{14}$.

Además de las exenciones descritas, la Comisión sobre Fiscalidad estudió la posibilidad de que quedaran exentas empresas que tuvieran compromisos voluntarios y legalmente vinculantes de reducir sus emisiones de $\mathrm{CO}_{2}$ con el regulador medioambiental SEAI (Sustainable Energy Authority of Ireland). Este esquema podría ofrecer alternativas a muchas de las instalaciones industriales de tamaño mediano y grande que no estaban sujetas al RCDE-UE. Finalmente, no se incluyó este tipo de exención en el diseño final del impuesto (Convery, 2014).

La mayor parte de la recaudación fiscal derivada del impuesto al carbono procede de la gasolina y del diésel para automoción (55\% en 2017), seguido del resto de combustibles líquidos y gaseosos. Los combustibles sólidos (carbón y turba) aportaban aproximadamente un 5,5\% de los ingresos totales asociados al impuesto.

Tabla 8. Ingresos del impuesto al carbono en Irlanda por tipo de combustible (millones de euros)

\begin{tabular}{|c|c|c|c|c|c|c|c|c|c|c|c|}
\hline 疋 & 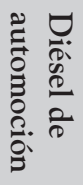 & 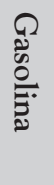 & 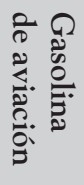 & $\begin{array}{l}0 \\
0 \\
0 \\
0 \\
0 \\
0 \\
0 \\
0\end{array}$ & 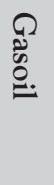 & $\begin{array}{l}\text { T. } \\
\text { है } \\
\frac{0}{0}\end{array}$ & 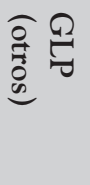 & 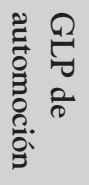 & 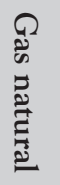 & $\begin{array}{l}\frac{1}{0} \\
\frac{0}{0} \\
0 \\
0 \\
0 \\
0 \\
0\end{array}$ & 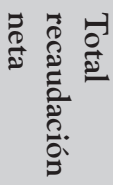 \\
\hline 2010 & 98 & 65 & 0,04 & 17 & 27 & 1,6 & 2,6 & 0,01 & 11 & - & 223 \\
\hline 2011 & 98 & 60 & 0,04 & 41 & 49 & 2,3 & 5,6 & 0,01 & 43 & - & 298 \\
\hline 2012 & 131 & 75 & 0,05 & 40 & 55 & 2,3 & 6,5 & 0,03 & 45 & - & 354 \\
\hline 2013 & 137 & 70 & 0,03 & 47 & 60 & 2,3 & 7,6 & 0,07 & 57 & 7,3 & 388 \\
\hline 2014 & 145 & 66 & 0,02 & 42 & 54 & 1,8 & 7,6 & 0,11 & 52 & 17,2 & 385 \\
\hline 2015 & 158 & 62 & 0,05 & 53 & 55 & 2,0 & 8,4 & 0,14 & 57 & 23,5 & 419 \\
\hline 2016 & 171 & 59 & 0,04 & 53 & 56 & 2,2 & 8,8 & 0,14 & 56 & 24,4 & 430 \\
\hline 2017 & 187 & 57 & 0,04 & 54 & 58 & 1,7 & 8,9 & 0,14 & 54 & 24,3 & $445^{*}$ \\
\hline
\end{tabular}

Nota: *=estimado.

Fuente: (Tax Strategy Group, 2017).

${ }^{14}$ (Convery, 2014). 


\section{DESTINO DE LA RECAUDACIÓN DEL IMPUESTO}

La recaudación del impuesto sobre el carbono en Irlanda se integra de manera general en los presupuestos del Estado, sin que se dediquen cantidades concretas a la consecución de objetivos específicos, medioambientales o de cualquier otra índole.

Pese a todo, en el momento de su aprobación, los documentos oficiales mostraban sensibilidad por algunas cuestiones medioambientales y de equidad y señalaban algunas vías para mitigar las consecuencias distributivas de la aplicación del impuesto. Así, en la presentación de los Presupuestos de 2010 (Budget Financial Statement) se indicaba que "...los ingresos del Impuesto sobre el Carbono se utilizarán para fomentar la eficiencia energética, dar apoyo al transporte en áreas rurales y combatir la pobreza energética. El Impuesto sobre el Carbono permitirá también mantener o reducir los impuestos sobre el trabajo...". Además, se indicaba que "...se desarrollará un esquema de cheque de energía para compensar a las familias con menores ingresos por los incrementos de costes del carbón y la turba...”; esquema similar al que ha desarrollado Francia, tal y como se verá más adelante.

Así, en los Presupuestos de 2010 se destinaron 50 millones de euros de los ingresos del impuesto sobre el carbono a programas de ayuda a los hogares más vulnerables (Better Energy Warmer Homes Scheme), a inversiones en eficiencia energética (Home Energy Saving Scheme) y se amplió el esquema existente de bonos de energía (National Fuel Allowance) hasta $20 € /$ semana durante 32 semanas en invierno.

\section{EFECTOS DE LA INTRODUCCIÓN DEL IMPUESTO SOBRE EL CARBONO}

A diferencia del caso de Suecia, la historia del impuesto sobre el carbono en Irlanda es una historia de éxito parcial. Su introducción se llevó a cabo en un momento en el que la crisis económica y financiera obligaba al Gobierno irlandés a incrementar la recaudación fiscal. Así, el impuesto sobre el carbono fue una medida más entre otras muchas, por lo que, a pesar de su impacto sobre la capacidad económica de los ciudadanos, no se enfrentó a una oposición frontal por parte de la sociedad irlandesa.

A ello contribuyeron tanto la sensibilidad social y política en torno al objetivo medioambiental de reducir las emisiones de $\mathrm{CO}_{2}$, como el hecho de que determinados sectores que se oponían a este tipo de imposición fiscal (i.e. agricultura o transporte) obtuvieran exenciones. 
Los efectos redistributivos derivados de la introducción de un impuesto al carbono y, en general, de la reforma fiscal que se aprobó en 2009, fueron ampliamente estudiados en Irlanda antes de su entrada en vigor. Así, debido a la preocupación por los efectos redistributivos (regresivos) derivados de la introducción de un impuesto al carbono, se pusieron en marcha diversos programas de apoyo a los hogares adicionales a los ya existentes.

El impuesto sobre el carbono, asumido y aceptado por la sociedad irlandesa, ha supuesto una relevante fuente de ingresos fiscales para el Gobierno, recaudando más de 2.000 millones de euros acumulados desde su introducción en 2009, y es en este sentido en el que cabe interpretar que la introducción del impuesto ha tenido éxito.

Sin embargo, la aplicación de esta medida no ha cumplido con el principal objetivo medioambiental (reducir las emisiones de gases de efecto invernadero) ni ha conseguido impulsar la transformación del sector energético (con una cuota muy elevada de los combustibles fósiles, especialmente gas natural, carbón y turba) o el mix de combustibles utilizados para calefacción (entre los que destaca la turba) ${ }^{15}$.

En los últimos años, los resultados que ha obtenido Irlanda en términos de emisiones de $\mathrm{CO}_{2}$ han sido poco satisfactorios (las emisiones comenzaron a crecer a partir de 2012 tras haber caído desde 2008) y las previsiones más recientes muestran un incremento esperado en las emisiones totales de $\mathrm{CO}_{2}$ hasta 2025. A ello contribuye, en gran medida, el crecimiento de las emisiones en el sector del transporte; por lo que es posible que no pueda alcanzar los objetivos fijados por la Unión Europea bajo el Mecanismo de Reparto de Esfuerzos (Effort Sharing Regulation, ESR) para $2020^{16}$, con un coste adicional asociado al incumplimiento que podría rondar entre los 200 y los 600 millones de euros/año ${ }^{17}$. Los objetivos de reducción de emisiones de $\mathrm{CO}_{2}$ para 2030 (30\% respecto a 2005 para los sectores que no están sujetos al RCDE-UE), aprobados en mayo de 2018 por la UE, parecen fuera del alcance de Irlanda en estos momentos.

En este contexto, se generó una fuerte presión sobre el Gobierno irlandés para que aprobara un incremento del tipo impositivo del impuesto sobre el carbono. El Consejo Asesor sobre Cambio Climático (Climate Change

\footnotetext{
${ }^{15}$ En 2016, el 6,8\% de la energía consumida en calefacción procedía de fuentes renovables.

${ }^{16}$ Irlanda tiene un objetivo vinculante de reducir las emisiones de gases de efecto invernadero en 2020 para el conjunto de sectores difusos (agricultura, transporte, sectores residencial y comercial, industria no intensiva en energía y sector de los residuos) un $20 \%$ por debajo del nivel registrado en 2005.

${ }^{17}$ (Department of Public Expenditure and Reform, 2014); (Curtin, 2016); (Committee of Public Accounts, 2018).
} 
Advisory Council, CCAC), creado por la Ley de Desarrollo con Bajas Emisiones (Low Carbon Development Act) de 2015, en su informe correspondiente a 2018, recomendaba elevar el tipo impositivo del impuesto sobre el carbono a $30 € / \mathrm{tCO}_{2}$ en 2019 y, posteriormente, incrementarlo gradualmente hasta $80 € / \mathrm{tCO}_{2}$ en 2030 (CCAC (Climate Change Advisory Council), 2018). Esta recomendación encajaba con la recomendación del Tax Strategy Group de fijar una senda de evolución del impuesto a largo plazo que aporte certidumbre y genere incentivos para tomar decisiones de inversión en eficiencia energética y energías renovables.

En octubre de 2019 el ministro de finanzas anunció un aumento del impuesto sobre el carbono de seis euros cada año, hasta alcanzar los $80 € / \mathrm{tCO}_{2}$ en 2030 . El incremento de $6 € / \mathrm{tCO}_{2}$ en 2020 aumentará la imposición sobre los combustibles para automoción en un 30\% lo que generará ingresos adicionales entre 90 y 130 M€. Además, el Gobierno ha desarrollado la estrategia medioambiental irlandesa bajo el marco del proyecto Irlanda 2040 (Project Ireland 2040).

\section{LA FISCALIDAD SOBRE EL CARBONO EN FRANCIA}

La introducción de la imposición sobre el carbono es una cuestión más reciente en el caso de Francia. El Ministerio de la Transición Ecológica y Solidaria (Ministère de la Transition écologique et solidaire) trata de promover el empleo de instrumentos económicos con el fin de favorecer la transición ecológica y modificar el comportamiento de los agentes económicos, como complemento de la regulación y de otros mecanismos voluntarios de reducción de las emisiones de gases de efecto invernadero. Entre estos instrumentos económicos, la fiscalidad medioambiental ocupa un papel relevante (Ministère de la Transition Écologique et Solidaire, 2018a; Ministère de la Transition Écologique et Solidaire, 2018b).

El conjunto de los impuestos medioambientales genera un volumen significativo de ingresos presupuestarios, que supusieron en Francia, en 2016, alrededor de 50.000 millones de euros. 
Tabla 9. Principales impuestos medioambientales en 2016

\begin{tabular}{|c|c|c|c|}
\hline Nombre & $\begin{array}{l}\text { Ingresos } \\
2016 \\
\text { (en millones } \\
\text { de euros) }\end{array}$ & $\begin{array}{c}\% \\
\text { respecto } \\
\text { al total }\end{array}$ & $\begin{array}{l}\text { Clasificación } \\
\text { Eurostat y peso } \\
\text { del concepto }\end{array}$ \\
\hline $\begin{array}{l}\text { Impuesto interior sobre el consumo de productos ener- } \\
\text { géticos (Taxe intérieure sur la consommation de produits } \\
\text { énergétiques, TICPE) }\end{array}$ & 28.456 & $55,5 \%$ & \multirow{6}{*}{$\begin{array}{l}\text { Energía } \\
(82,6 \%)\end{array}$} \\
\hline $\begin{array}{l}\text { Contribución al servicio público de la electricidad (Contri- } \\
\text { bution au service public de l'électricité, CSPE) }\end{array}$ & 8.264 & $16,1 \%$ & \\
\hline Impuestos locales sobre la electricidad & 1.588 & $3,1 \%$ & \\
\hline $\begin{array}{l}\text { Impuesto fijo sobre las empresas de redes (Imposition for- } \\
\text { faitaire sur les entreprises de réseaux, IFER) }\end{array}$ & 1.592 & $3,1 \%$ & \\
\hline $\begin{array}{l}\text { Impuesto interior sobre el consumo de gas natural (Taxe } \\
\text { intérieure de consommation sur le gaz natural, TICGN) }\end{array}$ & 1.104 & $2,2 \%$ & \\
\hline Otros impuestos energéticos & 1.310 & $2,6 \%$ & \\
\hline $\begin{array}{l}\text { Impuesto sobre los certificados de matriculación (Taxe } \\
\text { sur certificats d'immatriculation, cartes grises) }\end{array}$ & 2.187 & $4,3 \%$ & \multirow{6}{*}{$\begin{array}{l}\text { Transporte } \\
(11,5 \%)\end{array}$} \\
\hline $\begin{array}{l}\text { Impuesto adicional sobre los seguros de vehículos (Taxe } \\
\text { additionnelle sur les assurances automóviles) }\end{array}$ & 996 & $1,9 \%$ & \\
\hline $\begin{array}{l}\text { Impuestos a pagar por concesionarias de autopistas (Taxe } \\
\text { due par les concessionnaires d'autoroute) }\end{array}$ & 599 & $1,2 \%$ & \\
\hline $\begin{array}{l}\text { Impuesto sobre los vehículos de empresa (Taxe sur les } \\
\text { véhicules de société, TVS) }\end{array}$ & 542 & $1,1 \%$ & \\
\hline Impuesto de la aviación civil (Taxe de l'aviation civile) & 410 & $0,8 \%$ & \\
\hline Otros impuestos sobre el transporte & 1.167 & $2,3 \%$ & \\
\hline $\begin{array}{l}\text { Canon sobre la contaminación del agua (Redevances } \\
\text { pollution eau) }\end{array}$ & 1.960 & $3,8 \%$ & \multirow[b]{2}{*}{$\begin{array}{l}\text { Contaminación } \\
\qquad(5,1 \%)\end{array}$} \\
\hline $\begin{array}{l}\text { Impuesto general sobre actividades contaminantes } \\
\text { [TGAP] (residuos, contaminación atmosférica, etc.) } \\
\text { excepto la TGAP sobre carburantes (Taxe générale sur } \\
\text { les activités polluantes }{ }^{18} \text { [TGAP] (déchets, pollutions atmos- } \\
\text { phériques...) hors TGAP carburant) }\end{array}$ & 654 & $1,3 \%$ & \\
\hline Canon sobre extracción de agua (Redevances prélèvement eau) & 385 & $0,8 \%$ & \multirow{2}{*}{$\begin{array}{l}\text { Recursos } \\
(0,8 \%)\end{array}$} \\
\hline Otros impuestos sobre los recursos & 22 & $<0,1 \%$ & \\
\hline Total (Eurostat) & 51.235 & $100,0 \%$ & \\
\hline $\begin{array}{l}\text { Impuestos y canon sobre recogida de residuos domésticos } \\
\text { (Taxe et redevance d'enlèvement des ordures ménagères, } \\
\text { TEOM et REOM) }\end{array}$ & 7.384 & & $\begin{array}{l}\text { Fuera de la } \\
\text { clasificación } \\
\text { de Eurostat }\end{array}$ \\
\hline
\end{tabular}

Fuente: elaboración propia a partir de Ministère de la Transition Écologique et Solidaire, 2018a; Ministère de la Transition Écologique et Solidaire (2018b).

18 La Ley de Presupuestos de 2016 rectificativa planteó un aumento de este impuesto, en lo que se refiere a residuos y no a carburantes. 
Como puede observarse en la tabla anterior, los principales impuestos medioambientales han sido aquellos sobre la energía, que supusieron el $82,6 \%$ del total en 2016, habiendo alcanzado un máximo del 85,3\% en 2003 y un mínimo del 76,9\% en 1996. En segundo lugar se encuentran los impuestos sobre el transporte, que no incluyen los impuestos sobre carburantes, con una aportación promedio del 13,4\% (11,5\% en 2016). No obstante, se observa una ligera tendencia decreciente de su peso en la recaudación total, no así del volumen en términos absolutos, que se mantiene relativamente estable.

Si bien la recaudación prácticamente no ha cesado de aumentar a lo largo de las dos últimas décadas, la ratio impuestos medioambientales sobre PIB cayó a niveles mínimos en 2008, momento a partir del cual se ha ido recuperando, pero sin alcanzar los niveles de los años noventa. La caída del peso se debió a la "dieselización" del parque automovilístico (históricamente menos gravado) así como a la falta de indexación a los precios de la energía de la mayoría de estos impuestos. De igual manera, el consumo de energía ha ido aumentando menos rápidamente que el PIB, como consecuencia del desacoplamiento parcial entre crecimiento económico y necesidades de energía, gracias a una mejora de la eficiencia energética (Service de l'économie, de l'évaluation et de l'intégration du développement durable, 2017).

\section{CRONOLOGÍA DE LA FISCALIDAD SOBRE EL CARBONO EN FRANCIA}

Durante los años ochenta y noventa, Francia desarrolló un conjunto de impuestos medioambientales con objetivos específicos, pero sin una clara relación con la protección medioambiental, hasta que, en 1999, adoptó el impuesto general sobre actividades contaminantes (taxe générale sur les activités polluantes, TGAP), con el doble objetivo de racionalizar el sistema impositivo medioambiental y de introducir el principio de "quien contamina paga".

Ante las indicaciones de la Mission interministérielle de l'effet de serre (Comisión interministerial sobre el efecto invernadero, MIES) de que el TGAP no era suficiente para alcanzar los compromisos de reducción de emisiones del Protocolo de Kioto (Rogissart, Postic, \& Grimault, 2018), el Gobierno decidió extender este impuesto al sector energético mediante un impuesto sobre el carbono, que destinaría una parte de la recaudación al fondo de compensación de la Seguridad Social para financiar la entonces nueva política de la semana laboral de 35 horas.

A pesar de que varios agentes económicos y grandes grupos industriales reaccionaron contra este proyecto de ley, en diciembre de 2000 se adoptó este nuevo impuesto, extendiendo el alcance del TGAP y planificando numerosas exenciones/reducciones para facilitar su aceptabilidad. Ante estas exenciones, la oposición política acudió al Tribunal Constitucional en busca de su invalidación, que llegó en diciembre de 2000 (2000-441 DC) por violación del principio de igualdad (del artículo 13 de la Declaración francesa de los derechos del hombre y ciudadano de 1789). 
Tras este fracaso, el impuesto sobre el carbono quedó fuera de la agenda política hasta que durante la campaña electoral de 2007 Nicolas Hulot ${ }^{19}$ solicitó a los candidatos firmar el "Pacto ecológico", un documento que contenía objetivos y medidas medioambientales, entre ellas la adopción de un impuesto al carbono creciente en el tiempo.

Nicolas Sarkozy, al ser elegido presidente de la República, intentó materializar su agenda medioambiental a través de un debate (Grenelle de l'environnement) entre diferentes agentes. Como resultado del debate se decidió crear un impuesto clima/energía sobre los combustibles fósiles. Dos años después, el 23 de julio de 2009 se adoptó la Ley Grenelle I, donde se fijaron objetivos medioambientales, como paliar el cambio climático. Una de las medidas para alcanzarlos era adoptar un futuro impuesto al carbono.

A diferencia de la propuesta anterior, este impuesto se centraba en los combustibles fósiles y contaba con esquemas de compensación teniendo en cuenta situaciones particulares. Sin embargo, los conductores percibieron que ellos iban a soportar la carga de la reducción del impuesto profesional. Pese al incipiente malestar, el Presidente anunció el impuesto y, como era previsible, el resultado fue un bajo nivel de aceptación (Rocamora, 2017).

Si bien el impuesto fue adoptado por la Ley de Presupuestos de 2010 con un precio de $17 € / \mathrm{tCO}_{2}$, fue posteriormente invalidado por el Tribunal Constitucional, argumentando que las exenciones planteadas eran contrarias al objetivo de mitigación de cambio climático y al principio de equidad impositiva (entre ciudadanos y empresas). En marzo de 2010, el Gobierno abandonaba este proyecto de impuesto sobre el carbono.

Con anterioridad a las elecciones presidenciales de 2012, Hollande declaró como una prioridad de su candidatura la transición energética y ecológica de la economía. El acuerdo firmado entre los partidos socialista y verde incluía la propuesta de una contribución clima-energía (CCE) con un precio del carbono que iría incrementándose.

En junio de 2013, algunos miembros del Parlamento solicitaron la introducción de una CCE, con un tipo impositivo creciente, así como el ajuste de los tipos impositivos entre gasolina y diésel. En respuesta, el Ministro de Medio Ambiente, Philippe Martin, anunció en agosto de 2013 la intención de crear una CCE e incluirla en la Ley de Presupuestos de 2014. En septiembre de 2013, Hollande confirmó el plan del Gobierno de introducir un componente de carbono en la Ley de Presupuestos de 2014, que serviría para financiar la transición energética. Dicha Ley se aprobó en diciembre de 2013.

${ }^{19}$ Entonces figura ecologista y posteriormente Ministro de la transición energética y solidaria entre 2017 y 2018. Presentó su dimisión en agosto de 2018. 
La fiscalidad sobre el carbono. Una aproximación a los casos de Suecia, Irlanda y Francia

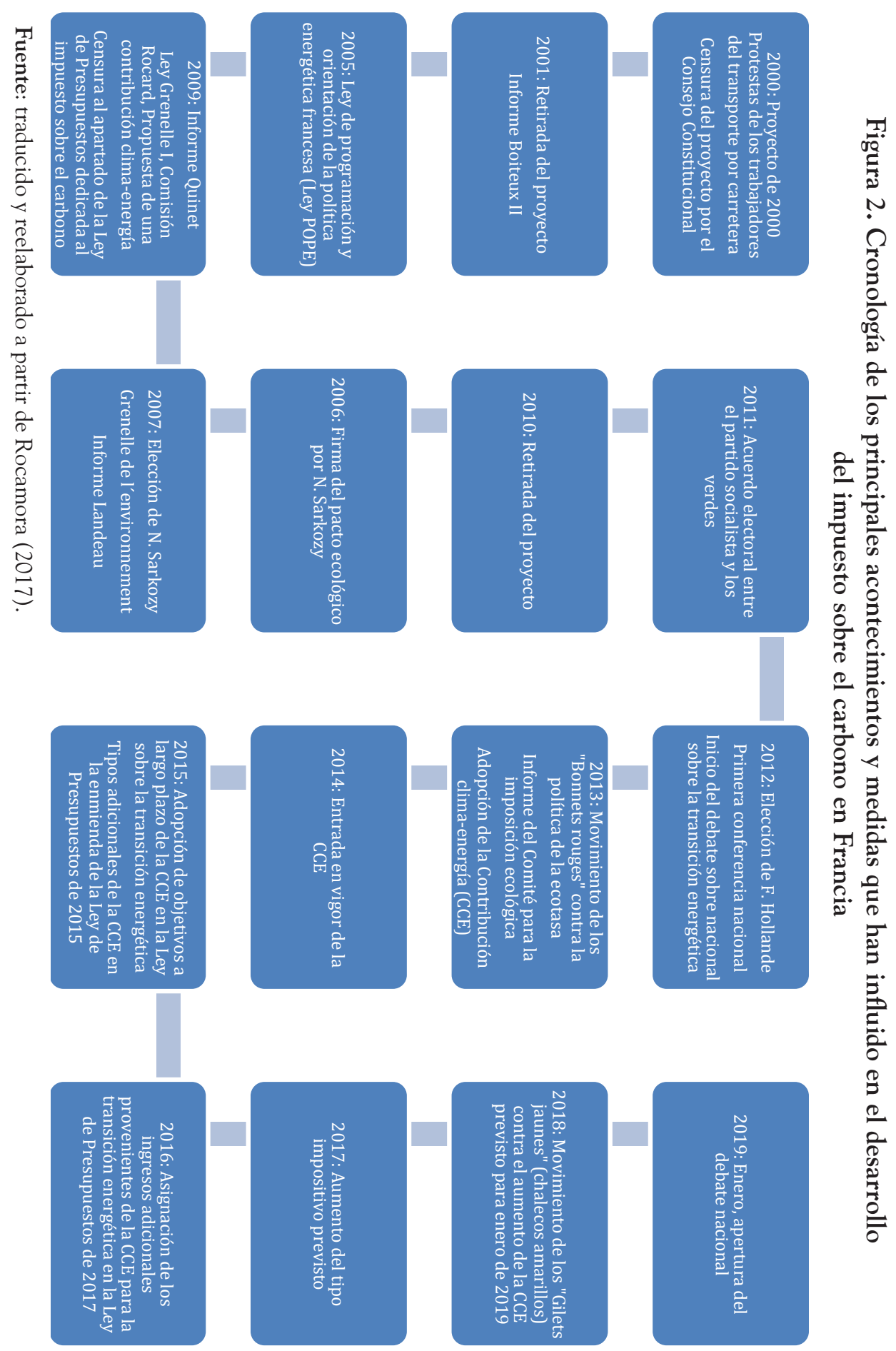

icade. Revista cuatrimestral de las Facultades de Derecho y Ciencias Económicas y Empresariales, $n^{\circ} 108$ septiembre-diciembre 2019, ISSN: 2341-0841 


\section{LA CONTRIBUCIÓN CLIMA-ENERGÍA O COMPONENTE DE CARBONO FRANCÉS}

Tal y como se sugirió, la CCE no se constituyó como un nuevo impuesto, sino como un componente, que se relaciona con el carbono, de impuestos existentes (TICPE, TICGN y TICC). Como consecuencia, la CCE no se ve afectada por la variación del precio de los productos energéticos gravados y es independiente de los impuestos en los que se incluye.

En paralelo, el Gobierno adoptó a partir 2014 una política de convergencia de la imposición de la gasolina y el gasóleo. Ello se debía a que, a pesar de que los vehículos de gasóleo generan más problemas de contaminación del aire en entornos urbanos que los vehículos a gasolina, debido a mayores emisiones de $\mathrm{NO}_{\mathrm{x}}$ y partículas, la fiscalidad sobre los carburantes estaba pensada para promocionar la venta de vehículos de diésel, con menores emisiones de $\mathrm{CO}_{2}$, y, por ello, el gasóleo estaba menos gravado que la gasolina.

En 2015 se publicó la Ley de transición energética para el crecimiento verde, que planteaba en su artículo primero una trayectoria creciente del componente de carbono hasta 2030.

\section{Gráfico 4. Progresión de la CCE prevista en la Ley de transición ecológica}

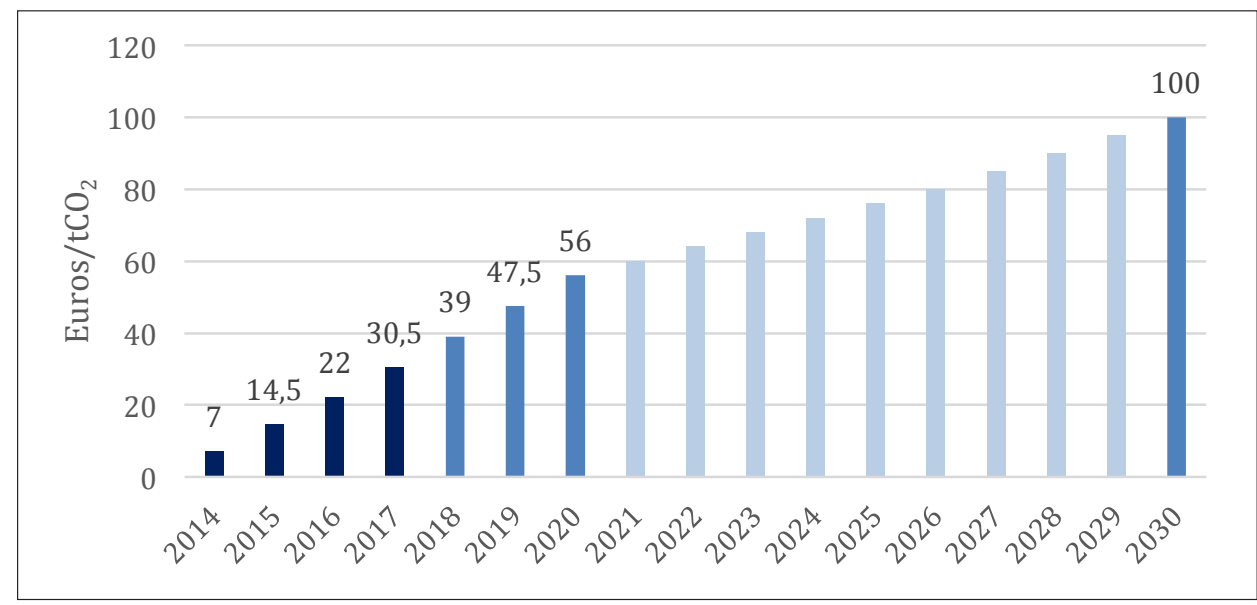

Nota 1: los colores más oscuros son datos históricos, los intermedios los planteados y los claros los estimados en coherencia con los anteriores.

Nota 2: los valores hasta 2019 se establecieron por las sucesivas Leyes de Presupuestos.

Fuente: Loi de finances 2014 en Rocamora (2017). 
Estos valores se fijaron a partir del "valor tutelar del carbono" (valeur tutélaire du carbone) establecido por el Centro de Análisis Estratégico (misión presidida por Alain Quinet de 2008; Ministère de la Transition Écologique et Solidaire, 2017). En la redacción de los presupuestos de 2018 se barajó abandonar el empleo de una trayectoria del precio del carbono para fijar el valor de los impuestos en cada Ley de presupuestos. No obstante, se descartó porque el uso de la trayectoria es una herramienta para ofrecer a los agentes económicos una referencia para que decidan las inversiones que consideren necesarias.

Tabla 10. Evolución del componente de carbono del TICPE en euros/tonelada de $\mathrm{CO}_{2}$

\begin{tabular}{|c|c|c|c|c|c|c|}
\hline Año & 2017 & 2018 & 2019 & 2020 & 2021 & 2022 \\
\hline Tipo & 30,5 & 44,6 & 55 & 65,4 & 75,8 & 86,2 \\
\hline
\end{tabular}

Fuente: (Ministère de la Transition Écologique et Solidaire, 2018b ; Ministère de la Transitions Écologique et Solidaire, 2018).

Como consecuencia de la naturaleza de la CCE como componente de unos impuestos previamente existentes, las exenciones son básicamente las mismas que las recogidas en el proyecto de impuesto sobre el carbono de 2009, dado que el legislador pretendía proteger a los sectores más vulnerables.

Entre los sectores exentos se encuentran las compañías bajo el RCDE-UE, las de transporte por carretera de mercancías, los operadores de transporte público, los taxistas y granjeros, el transporte fluvial de mercancías, el transporte aéreo de pasajeros, los pesadores y los fletadores. También se aplican tipos especiales a determinados productos y actividades energéticas, como la generación eléctrica y la extracción y producción de gas natural.

En total, en Francia la CCE cubre 180.000 millones de toneladas de $\mathrm{CO}_{2 \mathrm{eq}}$, es decir, aproximadamente el $40 \%$ de las emisiones del país. Como consecuencia de las exenciones, dos tercios de los ingresos fiscales por la CCE provienen de los hogares y el tercio restante de las empresas. En todo caso, y a pesar de las exenciones, se considera que la imposición sobre el carbono en Francia presenta una gran cobertura en comparación con otros impuestos sobre el carbono (OECD, 2018).

\section{DESTINO DE LA RECAUDACIÓN PROCEDENTE DE LA CCE. EL NUEVO ENFOQUE EN FRANCIA}

Con la CCE podría decirse que Francia pasó de una fiscalidad medioambiental basada en el doble dividendo a una basada en la asignación de los fondos recaudados 
a fines concretos. La particularidad de la CCE es que su estructura fue adoptada en el seno de una legislación de transición energética y, por ello, la CCE podría verse no solo como un instrumento para reducir emisiones de GEI, sino también como motor de cambio.

Así, una parte de los ingresos del TICPE se destinan a la compte d'affectation spéciale Transition Énergetique (cuenta de afectación especial para la transición energética, CAS-TE, cuyo objetivo principal es respaldar el desarrollo de la energía eléctrica renovable), junto con una parte residual de la recaudación del TICC y de la subasta de las garantías de origen renovable.

Otra parte de los ingresos obtenidos de la recaudación de la CCE tiene como beneficiarios a aquellos hogares más expuestos al impacto de la fluctuación de los precios de la energía, y a las pequeñas y medianas empresas sin apoyo público.

El Gobierno francés, con anterioridad a dicho reconocimiento oficial, había observado ya la necesidad de facilitar el acceso a la energía a determinados segmentos de la población (hogares) que se enfrentaban a serias dificultades para hacer frente a sus facturas e implementó una serie de medidas a tal fin. De hecho, en 2005 y 2008 se crearon las tarifas sociales para gas y electricidad dirigidas a hogares con bajos ingresos. Con posterioridad, la Ley de transición energética anunció la introducción paulatina del denominado Cheque Energía para el pago de sus gastos energéticos (facturas y acometida de mejoras), que sustituyó definitivamente a las tarifas sociales de electricidad y gas en 2018.

\section{EFECTOS DE LA INTRODUCCIÓN DE LA CCE}

Con una entrada en vigor de la figura impositiva relativamente reciente en comparación con los casos de Suecia y de Irlanda, por el momento no puede decirse que la CCE haya promovido una mayor reducción de las emisiones de GEI. Los ingresos relacionados con la introducción del componente de carbono en la fiscalidad de la energía se estimaron en 300 millones de euros en 2014, 2.300 millones en 2015 y alrededor de 4.000 en 2016. En 2016, 700 millones se emplearon para reducir al 5,5\% el IVA aplicado a las actividades relacionadas con la renovación térmica de los edificios y a bienes y servicios esenciales para la transición energética (cuya definición está pendiente) y 300 millones se dedicaron a una política de redistribución proporcional a los niveles de ingresos.

Sin embargo, sí puede señalarse el efecto que ha tenido sobre la sociedad. Así, desde finales de 2018 y de manera recurrente los siguientes fines de semana durante varios meses, miles de personas se manifestaron en toda Francia, entre otros motivos, contra la subida del precio de los carburantes, como consecuencia de la fiscalidad. Los manifestantes eran fundamentalmente ciudadanos que empleaban el vehículo propio a diario y en zonas relativamente poco pobladas con menores servicios de transporte público. Este movimiento se denominó "chalecos amarillos" (Gilets jaunes). 
Como consecuencia, los principales representantes de la extrema derecha e izquierda del país solicitaron una moratoria de la nueva subida de impuestos verdes sobre gasolinas y gasóleo, prevista para enero de 2019, y el partido conservador de los republicanos insistió en la necesidad de convocar un referéndum sobre las políticas ecológica y fiscal del Gobierno.

Tras los primeros fines de semana de revueltas, el Gobierno francés anunció una moratoria de seis meses en la introducción de las nuevas tasas, que estaba prevista para enero de 2019 (Bassets, 2018). Esta suspensión de la subida de las tasas a los combustibles finalmente se convirtió en una anulación del aumento previsto para el año 2019.

Sin embargo, esta medida venía acompañada de otras como: la moratoria de la convergencia gasolina-gasóleo, la moratoria al aumento de la fiscalidad del gasóleo para profesionales (en el caso del gasóleo no empleado en carretera) y la congelación de los precios del gas y de la electricidad, dejando el Estado de recaudar 2.000 millones de euros (Gouvernement.fr, 2018).

A pesar de que algunos sectores consideran que la moratoria al aumento de la fiscalidad por la CCE podría hacer más frágil el sistema, se puede considerar que debido a que la fiscalidad medioambiental busca un determinado fin, esta moratoria podría ayudar a restaurar la confianza en el largo plazo en este instrumento de lucha contra las emisiones de GEI (Saujot, Berghmans \& Chancel, 2019).

En todo caso, las peticiones por parte de los manifestantes iban más allá de las relacionadas con la fiscalidad energética. Ante esta situación, el presidente de la República, Emmanuel Macron, convocó un gran debate en Francia cuyos resultados a la fecha de finalización de este artículo todavía no se han publicado.

No obstante, en febrero de 2019, el presidente de la República adelantó que no era posible volver a un esquema de aumento automático de la CCE, evocando la posibilidad de una fiscalidad que varíe en función de la evolución mundial de los precios del crudo y de los derivados del petróleo, lo que podría amortiguar el impacto de eventuales aumentos significativos de los precios de la energía sobre los precios de los combustibles en las estaciones de servicio (CBanque, 2019).

\section{A MODO DE CONCLUSIONES Y REFLEXIONES}

\section{SOBRE LA FISCALIDAD MEDIOAMBIENTAL}

La consecución de los ambiciosos objetivos medioambientales fijados por la estrategia de la Unión Europea de lucha contra el cambio climático y reflejados en la legislación de los Estados miembros requiere la aplicación de políticas complejas que integren distintos tipos de herramientas, medidas y programas. 
Tabla 11. Principales objetivos clima-energía

\begin{tabular}{|l|l|l|l|}
\hline \multicolumn{1}{|c|}{ Objetivos de energía-clima } & \multicolumn{1}{|c|}{ Suecia } & \multicolumn{1}{|c|}{ Irlanda } & \multicolumn{1}{c|}{ Francia } \\
\hline $\begin{array}{l}\text { Reducción de las emisiones de } \\
\text { gases de efecto invernadero en } \\
2020 \text { respecto de 1990 }\end{array}$ & $\begin{array}{l}40 \% \text { (respecto } \\
\text { a 1990 en sec- } \\
\text { tores difusos) }\end{array}$ & $\begin{array}{l}20 \% \\
\text { (respecto a 2005) }\end{array}$ & $\begin{array}{l}15 \% \\
\text { (respecto a 1990) }\end{array}$ \\
\hline $\begin{array}{l}\text { Cuota de energías renovables } \\
\text { en el consumo final de energía } \\
\text { en } 2020\end{array}$ & $50 \%$ & $\begin{array}{l}16 \% \\
-40 \% \text { en electricidad, } \\
-12 \% \text { en calefacción, } \\
-10 \% \text { en transporte }\end{array}$ & $\begin{array}{l}23 \% \\
\text { (respecto a 2012) }\end{array}$ \\
\hline $\begin{array}{l}\text { Mejora en la eficiencia energé- } \\
\text { tica reflejada en una reducción } \\
\text { de la intensidad energética }\end{array}$ & $\begin{array}{l}20 \% \text { (respecto } \\
\text { a 2008) }\end{array}$ & $20 \%$ & $20 \%$ \\
\hline $\begin{array}{l}\text { Objetivos a 2030 (para el con- } \\
\text { junto de la UE) }\end{array}$ & $\begin{array}{l}\text {-Reducción emisiones GEI: 40\% } \\
\text {-Renovables en consumo final de energía: 27\% } \\
\text {-Eficiencia energética: 27\% }\end{array}$ \\
\hline $\begin{array}{l}\text { Reducir en 2050 las emisiones } \\
\text { de gases de efecto invernadero } \\
\text { en la UE en comparación con } \\
\text { los niveles registrados 1990 }\end{array}$ & $80-95 \%$ de reducción \\
\hline
\end{tabular}

Fuente: elaboración propia.

Entre estas herramientas se encuentra el establecimiento de un precio a las emisiones de GEI que refleje su coste medioambiental y que debería estar coordinado con otras medidas, entre ellas las fiscales, y ser consistente con el esquema fiscal en conjunto para evitar efectos redistributivos no deseados.

La fiscalidad medioambiental no se basa únicamente en la fiscalidad energética, dado que en la práctica se aplica a cuatro grandes problemas medioambientales: el cambio climático, la contaminación, las amenazas sobre la biodiversidad y el consumo ineficiente de recursos naturales. Para cada uno de estos ámbitos existen distintos instrumentos fiscales en los países analizados, pero una parte de ellos se han mostrado incompletos, poco utilizados y mejorables (Service de l'économie, de l'évaluation et de l'intégration du développement durable, 2017).

De hecho, las experiencias internacionales y las evaluaciones económicas en el ámbito de la fiscalidad medioambiental muestran que su impacto global depende de numerosos factores.

En el caso de la figura del impuesto sobre el carbono, las experiencias presentadas muestran considerables diferencias. Una parte de las mismas dependen del año de implementación del impuesto. Como se puede observar, Suecia va por delante entre dos y tres décadas, lo que le ha permitido ir aumentando de forma gradual el tipo impositivo del impuesto a niveles ya elevados, en comparación con Irlanda y Francia. 
La fiscalidad sobre el carbono. Una aproximación a los casos de Suecia, Irlanda y Francia

Tabla 12. Año de implementación del impuesto y niveles mínimos y máximos

\begin{tabular}{|l|c|c|c|}
\cline { 2 - 4 } \multicolumn{1}{c|}{} & Suecia & Irlanda & Francia \\
\hline Año de implementación del impuesto & 1991 & 2010 & 2014 \\
\hline Mínimo $\left(€ / \mathrm{tCO}_{2}\right)$ & $8-33$ & 15 & 7 \\
\hline Máximo (año) $\left(€ / \mathrm{tCO}_{2}\right)$ & $120(2018)$ & $20(2018)$ & $44,6(2018)$ \\
\hline
\end{tabular}

Fuente: elaboración propia.

El tamaño de las tres economías también es diferente y ello, junto con el tipo impositivo, ha llevado a que las cifras de recaudación por el impuesto sobre el carbono sean diferentes. De hecho, la Comisión Europea estimó que, en los últimos años, había caído el peso de los ingresos por imposición medioambiental en relación con el PIB en Suecia, situándose en 2015 en torno al 2,2\% (frente a más del 2,5\% en 2010), por debajo del promedio de la Unión Europea. Según la Comisión, esto podría deberse también al cambio en el comportamiento de los consumidores (en parte relacionado con la imposición medioambiental) y al incremento en el uso de biocombustibles, especialmente en el sector del transporte, como alternativa a los combustibles fósiles tradicionales. No obstante, se mantiene por encima de los casos de Francia e Irlanda.

Gráfico 5. Ingresos por impuestos medioambientales como porcentaje del PIB en la Unión Europea (2010 y 2015)

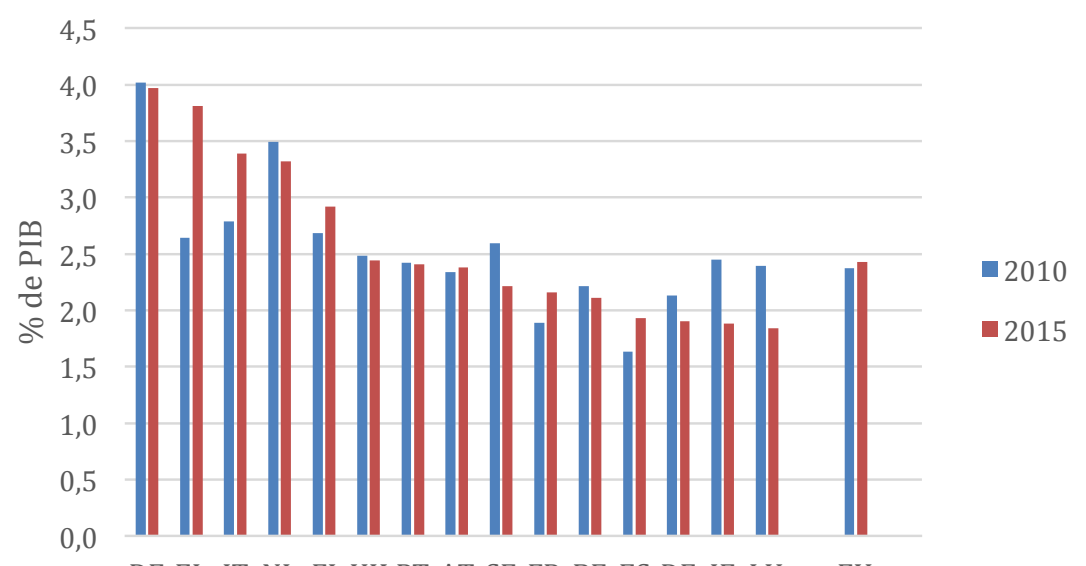

DE EL IT NL FI UK PT AT SE FR BE ES DE IE LU EU

Fuente: elaboración propia a partir de datos de Eurostat en Comisión Europea (2018a). 
Otro de los aspectos que deben tenerse en cuenta a la hora de evaluar los impuestos sobre el carbono se refiere a la manera en que se emplean los ingresos recaudados. En primer lugar, se pueden dedicar a reducir el déficit público, consolidando los presupuestos del Estado. También se pueden redistribuir los impuestos entre las empresas u hogares más afectados por el impuesto. La tercera opción sería reducir los impuestos sobre las personas físicas o jurídicas (por ejemplo: impuesto sobre sociedades o cotizaciones a la seguridad social por parte de las empresas) con el fin de relanzar la actividad y lograr un sistema económico más eficaz. Finalmente, pueden emplearse como instrumentos para alcanzar objetivos medioambientales concretos, financiando gastos o inversiones en preservación o recuperación del medio ambiente, o como una herramienta más de apoyo a políticas industriales, favoreciendo la innovación verde, las actividades relacionadas con la eficiencia energética, la economía circular o la expansión de las energías renovables, por ejemplo.

\section{LECCIONES POR PAÍS}

La facilidad de implementación del esquema fiscal sueco; los largos tiempos empleados; su efectividad en términos de costes de reducción de las emisiones de $\mathrm{CO}_{2}$, de adopción de medidas de eficiencia energética y de transformación del sistema energético en general; y el nivel de apoyo social son las principales dimensiones por las que puede considerarse un éxito el modelo fiscal sueco (Akerfeldt, 2016; Raab, 2017). Además de todo lo anterior, uno de los factores más relevantes para explicar el éxito de la estrategia energética y medioambiental de Suecia es su larga tradición como país pionero, a nivel mundial, en el desarrollo y adopción de estrategias y políticas medioambientales.

El fuerte apoyo social a políticas basadas en el principio de que "quien contamina paga" ha favorecido un conjunto de políticas fiscales que buscan el equilibrio macroeconómico a través del objetivo de neutralidad fiscal, trasladando a consumidores y empresas, simultáneamente, parte de los ingresos obtenidos en forma de tipos impositivos más bajos sobre el trabajo y la renta. En el caso de Suecia, la confianza de la población en las instituciones (y en un uso adecuado de los ingresos recaudados) es también otro factor que contribuyó a consolidar el esquema.

Asimismo, el aumento gradual en el tiempo del tipo impositivo y, muy especialmente, la existencia de alternativas de consumo energético con menores costes para los ciudadanos (district heating o transporte público) les han permitido a estos y a las empresas adaptar gradualmente sus comportamientos y consumos ante la nueva realidad impositiva, lo que ha atenuado el impacto sobre los segmentos de población y del tejido empresarial más expuestos a este cambio en la fiscalidad. La implicación de todo ello es que, además de tener un apoyo social robusto, la nueva figura fiscal medioambiental no se enfrentó a un rechazo social que minara la apuesta política por este tipo de soluciones. 
Como resultado, el modelo sueco de fiscalidad energética (junto con el resto de políticas energéticas y medioambientales -especialmente, las que inducían mejoras en la eficiencia energética y el cambio en los procesos productivos) ha obtenido los resultados medioambientales deseados, reduciéndose las emisiones de gases de efecto invernadero y la intensidad energética e impulsándose la penetración de energías renovables en todos los sectores de la economía, incluyendo la edificación, el transporte y la industria, y desacoplando la evolución del PIB de la evolución de las emisiones de GEI. Además, la consecución de estos objetivos y la mejora de la calidad del aire han favorecido una percepción generalizada de confianza y de apoyo al sistema implementado.

La situación en Irlanda es diferente. En el caso irlandés, pese a introducirse un esquema de imposición medioambiental de forma exitosa (aunque con un objetivo claro de incrementar los ingresos fiscales), no se avanzó en la implementación del mecanismo en la última década y el apoyo social inicial (ligado a la concienciación medioambiental de la población) dio lugar a una oposición creciente a un incremento en la presión fiscal.

Así, en este caso se observa que la mera introducción de un impuesto sobre el carbono, sin apoyarse en una política energética y medioambiental que continúe proyectando hitos a futuro, no es suficiente para alcanzar reducciones en las emisiones de GEI y transformaciones profundas en el uso de la energía en sectores como la edificación o el transporte, o en los procesos productivos y energéticos en la industria.

De esta manera, sin una agenda política ambiciosa y el respaldo y la concienciación de la sociedad, resulta complicado avanzar en la implementación de señales fiscales que induzcan cambios en la estructura de la matriz energética, incrementando el peso de las energías limpias y mejorando la eficiencia energética.

Como resultado de todo ello, en la actualidad Irlanda se ve inmersa en una encrucijada, con un elevado riesgo de incumplimiento de los objetivos del paquete de medidas sobre clima y energía para 2020 y sin haber puesto en marcha, hasta ahora, una estrategia a más largo plazo para reducir las emisiones de GEI, lo que se traducirá en la adopción, en el corto plazo, de medidas con gran impacto sobre la economía irlandesa, incluyendo la subida en el tipo impositivo del impuesto sobre el carbono.

El caso de Francia es el más reciente y puede resultar más difícil extraer conclusiones para el mismo. No obstante, los sucesivos fracasos en los intentos de introducir la imposición sobre el carbono (años 2000 y 2009) y que deberían contemplarse como lecciones para la implementación final del mismo, no han sido suficientes para la adopción de un impuesto que convenza a la población, a pesar de que en Francia algunas prioridades medioambientales están mejor consideradas por la población que en Irlanda, pero menos que en Suecia.

De hecho, en la encuesta Eurobarómetro Estándar de primavera de 2018 se observa que los ciudadanos suecos eran, en el seno de la UE, los que de forma mayoritaria consideraban prioritarias la lucha contra el cambio climático (54\% de los encuestados, 
frente a un $31 \%$ en promedio en la UE) y el desarrollo de las energías renovables (70\%, frente a un promedio del 44\% en la UE) como indica la siguiente figura.

\section{Tabla 13. Prioridades en una Unión de la Energía (\% de entrevistados que consideran cada asunto una prioridad)}

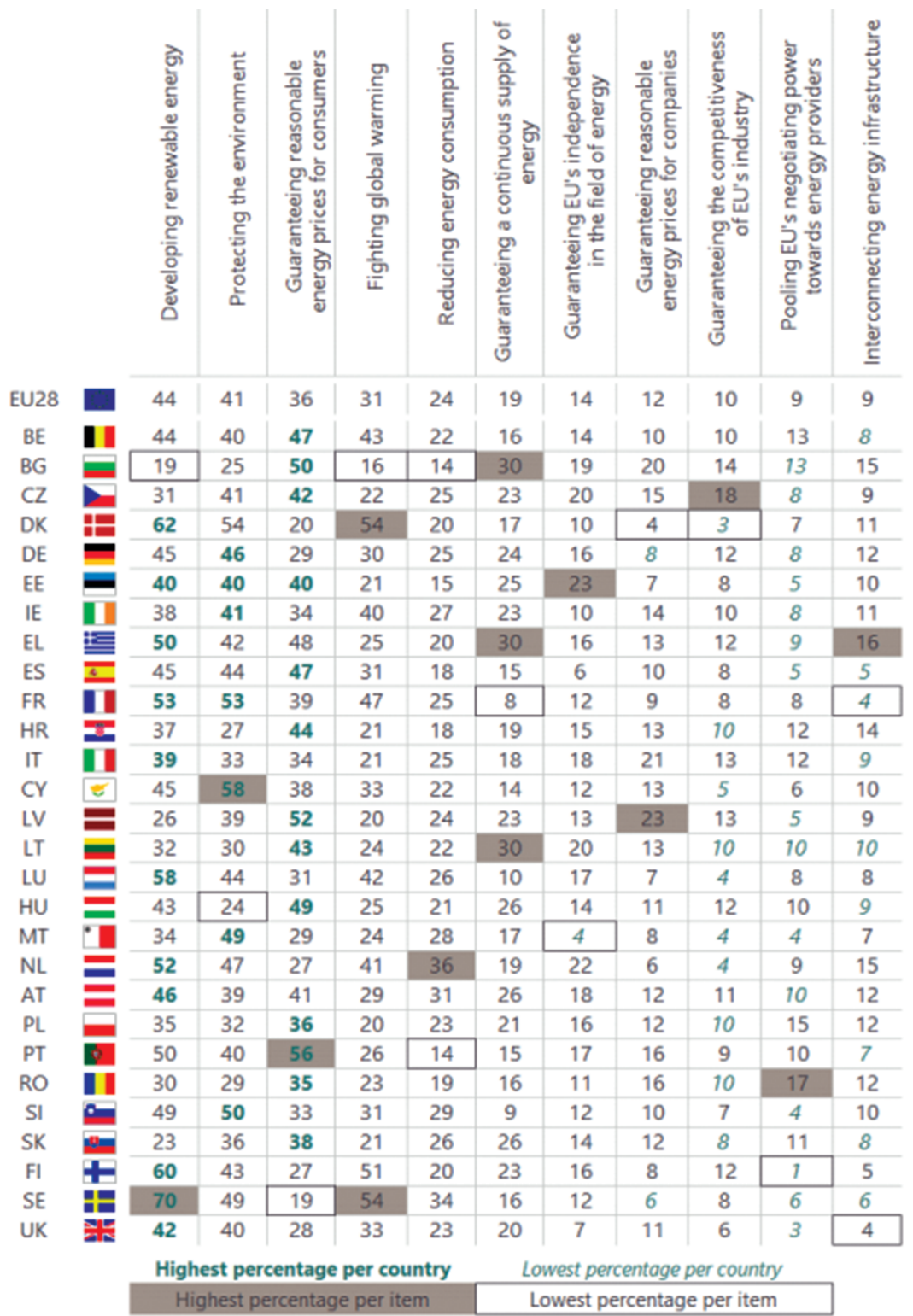

Fuente: Comisión Europea (2018c). 
Así, las revueltas de los "chalecos amarillos" en Francia sugieren que, en un contexto de crisis económica o de crecimiento económico limitado e incierto, una percepción social negativa o equivocada sobre el alcance y los objetivos de las reformas fiscales puede actuar como freno para la toma de decisiones en el ámbito político orientadas a alcanzar objetivos medioambientales o, en un escenario peor, puede motivar otras medidas fiscales con visión de corto plazo que generen, a largo plazo, una pérdida del bienestar social.

Por ello, los ciudadanos deben percibir que la nueva figura impositiva tiene un objetivo medioambiental y no meramente recaudatorio (por ejemplo, prevalecer, de forma general, el principio de que "quien contamina, paga") y que los sectores más afectados (p. ej., industrias más afectadas por la competencia internacional o consumidores domésticos en situación de pobreza energética) tendrán la protección de esquemas de "reciclado de ingresos" orientados a reducir los posibles efectos regresivos.

Así, resulta fundamental la aplicación de un criterio de equilibrio entre el mismo tipo de agentes (consumidores domésticos) y entre diferentes tipos de agentes (consumidores domésticos vs. empresas). Asimismo, se debe mejorar la transparencia en el uso de los ingresos procedentes de figuras fiscales medioambientales y deben existir mecanismos claros que garanticen que se minimizan los efectos redistributivos de la fiscalidad.

De esta manera, la aprobación e implementación de medidas fiscales de gran impacto económico puede resultar más o menos eficaz en función de qué otras medidas las acompañan. En este sentido, el establecimiento de un impuesto sobre el carbono en Suecia resultó positivo debido a la existencia de alternativas energéticas suficientemente económicas y de otras medidas y políticas orientadas a la transformación de los procesos de consumo de energía en los distintos sectores.

Por su parte, en el caso de Irlanda, era necesario un reajuste fiscal muy significativo (incremento de los ingresos fiscales y reducción del gasto social), la población no se opuso a la introducción del impuesto sobre el carbono, probablemente porque era considerado una medida más dentro de un gran paquete de ajustes, pero aquel no se desarrolló en los años posteriores a su introducción, como en el caso de Suecia, acompañado de medidas alternativas que indujeran transformaciones profundas en áreas relevantes (mix energético, procesos productivos en la industria, consumos en hogares y en el transporte), favorecieran el desarrollo de sectores alternativos que generaran valor añadido para la economía (p. ej., en energías renovables, eficiencia energética, economía circular...) y mitigaran el impacto del impuesto sobre los agentes económicos más expuestos al mismo.

Respecto del diseño de los esquemas fiscales basados en impuestos sobre el carbono, cabe señalar que la gradualidad en la aplicación de las señales económicas generadas (impuesto sobre el carbono); la transparencia, estabilidad y predictibilidad de su trayectoria; y el desarrollo de ayudas específicas para favorecer la transición energética de los agentes parecen ser elementos que pueden ayudar a 
que los agentes económicos tomen decisiones en el medio plazo que les permitan adaptarse al nuevo conjunto de señales económicas.

La evidencia empírica sugiere también que existen oportunidades para lograr un doble dividendo si las medidas fiscales energéticas y medioambientales se complementan con otras, bien orientadas, que reduzcan las pérdidas de bienestar social derivadas de los esquemas impositivos vigentes, aunque identificar las modificaciones Pareto-eficientes de la fiscalidad del trabajo (por ejemplo) requiere un análisis profundo de los impactos concretos de la estructura fiscal actualmente en vigor.

En conclusión, es fundamental diseñar políticas bien estudiadas y orientadas que, entre otras, incluyan medidas transitorias a corto plazo para las empresas, sectores y regiones adversamente afectadas y que ofrezcan incentivos, créditos u otros instrumentos, etc. para salvaguardar a las empresas y a la ciudadanía y ayudarles a superar las dificultades resultantes de sumarse al objetivo de construir una sociedad baja en carbono.

No obstante, la situación de partida, en todos los ámbitos de las diferentes economías, es muy diferente en los distintos países. En algunas economías, la fijación de objetivos cada vez más ambiciosos en un horizonte temporal de aproximadamente una década (periodo 2020-2030) implicaría la necesidad de empezar a actuar inmediatamente para garantizar un periodo de transición de algunos años para la industria, con lo que ello puede suponer en términos de coste e inversiones necesarias en el corto plazo. La revisión de casos de Suecia, Irlanda y Francia sugiere que es muy importante contar con plazos de implementación suficientes para llevar a cabo una transformación efectiva de los sistemas de producción y consumo, más en el caso de emplear una combinación de medidas alternativas.

\section{BIBLIOGRAFÍA}

Ackva, J. \& Hoppe, J. (2018). The carbon tax in Sweden. Factsheet. Recuperado de: https://www.euki.de/wp-content/uploads/2018/09/fact-sheet-carbontax-se.pdf Akerfeldt, S. (2016). Green fiscal reform. 17 th global conference on environmental taxation. Groningen, Netherlands. Recuperado de: http://www.greenfiscalpolicy. org/wp-content/uploads/2016/09/Susanne-Akerfeld Sweden.pdf

Andersson, J. (2017). Cars, carbon taxes and $\mathrm{CO}_{2}$ emissions. Centre for climate change economics and policy working paper no. 238, Grantham Research Institute on Climate Change and the Environment working paper no. 212. Recuperado de: http://www.lse.ac.uk/GranthamInstitute/wp-content/uploads/2017/03/Working-paper-212-Andersson update March2017.pdf 
Bassets, M. (2018, 04/12/2018). Macron cede ante los 'chalecos amarillos' y suspende el alza del impuesto a los carburantes. El País. Recuperado de: https://elpais.com/internacional/2018/12/04/actualidad/1543909722 922159.html

Bureau, D. (2013). Fiscalité verte et compétitivité: La démonstration suédoise. Références Économiques Pour Le Developpement Durable, 26.

CCAC (Climate Change Advisory Council). (2018). Annual report 2018. Ssubmitted to Government on 17 july 2018.

Central Statistics Office (CSO). (2018). Environment taxes 2017. CSO statistical release, 11 july 2018, 11am. Recuperado de: https://www.cso.ie/en/releasesandpublications/er/eaet/environmenttaxes2017/

Comisión europea. (2018a). Commission staff working document. Country report Sweden 2018 including an in-depth review on the prevention and correction of macroeconomic imbalances. SWD(2018) 225 final. Brussels. Recuperado de: https://ec.europa. eu/info/sites/info/files/2018-european-semester-country-report-sweden-en.pdf

Comisión europea. (2018b). Country report Ireland 2018. Including an in-depth review on the prevention and correction of macroeconomic imbalances. SWD(2018) 206 final.

Comisión europea. (2018c). Standard Eurobarometer 89. Spring 2018. The views of Europeans on the European Union's priorities. Recuperado de: http://ec.europa. eu/commfrontoffice/publicopinion

Commission on Taxation. (2009). Commission taxation report 2009. Recuperado de: https://researchrepository.ucd.ie/bitstream/10197/1447/1/Commission on Taxation Report 2009.pdf.

Committee of Public Accounts. (2018). PAC periodic report no.2, November-December 2017. 32/CPA/005. Recuperado de: https://govacc.per.gov.ie/wp-content/ uploads/PAC-Periodic-Report-9-Nov-to-14-Dec-2017-FINAL.pdf

Convery, F. e. a. (2013). Ireland's carbon tax and the fiscal crisis: Issues in fiscal adjustment, environmental effectiveness, competitiveness, leakage and equity implications. OECD Environment Papers, 59.

Convery, F. e. a. (2014). Ireland's carbon tax in the context of the fiscal crisis. Cyprus Economic Policy Review, 8 (2), 135.

Curtin, J. (2016). How much of Ireland's "fiscal space" will climate inaction consume? Recuperado de: www.irisheconomy.ie

Department of Employment Affairs and Social Protection. (2011). Over $€ 20.5$ billion to be spent on social protection in 2012. $€ 475$ million in savings to be achieved. Recuperado de: http://www.welfare.ie/en/pressoffice/Pages/No-cutsto-primary-weekly-social-welfare-rates--Minister-Bu.aspx

Department of Public Expenditure and Reform. (2014). Future expenditure risks associated with climate Change/Climate finance. Recuperado de: https://igees.gov. ie/wp-content/uploads/2013/10/Future-Expenditure-Risks-associated-with-Climate-Change-Climate-Finance1.pdf 
European Commission, Press release database. (1995). The Commission, acting on the proposal of $\mathrm{Mr}$ Monti, in agreement with Mrs Bjerregaard and $\mathrm{Mr}$ Papoutsis, has decided to amend its proposal for a Council directive introducing a tax on carbon dioxide emissions and energy, which it presented on 2 June 1992. Recuperado de: http://europa.eu/rapid/press-release IP-95-468 en.htm

Galindo, L. M., Beltrán, A., Ferrer Carbonell, J. \& Alatorre, J. E. (2017). Efectos potenciales de un impuesto al carbono sobre el producto interno bruto en los países de América Latina. Estimaciones preliminares e hipotéticas a partir de un metaanálisis y una función de transferencia de beneficios. Naciones Unidas-CEPAL. Recuperado de: https://repositorio.cepal.org/bitstream/handle/11362/41867/1/S1700590 es.pdf

Garrido, L. e. a. (2017). Efectos potenciales de un impuesto al carbono sobre el producto interno bruto en los países de América Latina. Estimaciones preliminares e hipotéticas a partir de un metaanálisis y una función de transferencia de beneficios. CEPAL: Naciones Unidas. Recuperado de: https://www.cepal.org/es/publicaciones/41867-efectos-potenciales-un-impuesto-al-carbono-producto-interno-bruto-paises-america

Gouvernement.fr. (2018). Le Premier ministre annonce un moratoire sur plusieurs mesures fiscales. Recuperado de: https://www.gouvernement.fr/le-premier-ministre-annonce-un-moratoire-sur-plusieurs-mesures-fiscales

Government Offices of Sweden. (2018). Sweden's carbon tax. Recuperado de: https:// www.government.se/government-policy/taxes-and-tariffs/swedens-carbon-tax/

Hammar, H., \& Akerfeldt, S. (2011). $\mathrm{CO}_{2}$ taxation in Sweden. 20 years of experience and looking ahead. Recuperado de: https://www.globalutmaning.se/wp-content/ uploads/sites/8/2011/10/Swedish Carbon Tax Akerfedlt-Hammar.pdf

Ireland 2050, E. I. (n.d.). The story of peat in Ireland. Recuperado de: http://ireland2050.ie/past/peat/

Larrea Basterra, M. (2018). El mercado europeo de derechos de emisión en la Unión Europea. En Sodupe, K. y Molina, G. (Ed.), Gobernanza para un sistema energético sostenible (pp. 327-361). UPV, Economía y Empresa.

Lin, B., \& Li, X. (2011). The effect of carbon tax on per capita $\mathrm{CO}_{2}$ emissions. Energy Policy, 39 (9), 5137.

Ministère de la Transition Écologique et Solidaire. (2017). Fiscalité carbone. Recuperado de: $\underline{\text { https://www.ecologique-solidaire.gouv.fr/fiscalite-carbone }}$

Ministère de la Transition Écologique et Solidaire. (2018a). Fiscalité des énergies. Recuperado de: https://www.ecologique-solidaire.gouv.fr/fiscalite-des-energies

Ministère de la Transition Écologique et Solidaire. (2018b). La fiscalité environnementale. Recuperado de: https://www.ecologique-solidaire.gouv.fr/fiscalite-environnementale OECD. (2018). Taxing energy use Sweden 2018. Recuperado de: https://www.oecd. org/tax/tax-policy/taxing-energy-use-2018-sweden.pdf

Pardo Martínez, C.I. \& Silveira, S. (2013). Energy efficiency and $\mathrm{CO}_{2}$ emissions in Swedish manufacturing industries. Energy Efficiency, 6 (1), 117. 
Perthuis, C. y Fauré, A. (2018). The 2018 finance bill: Towards a Swedish-style carbon tax? Climate Economics Chair Policy Brief n. 2018-1. ed. Recuperado de: https://www.chaireeconomieduclimat.org/en/publications-en/the-2018-financebill-towards-a-swedish-style-carbon-tax/

Raab, U. (2017). Carbon tax - determining the tax rate. swedish experiences. Recuperado de: https://www.thepmr.org/system/files/documents/Sweden\%20PMR\%20Technical\%20Workshop\%20on\%20Carbon\%20Tax\%2022\%20March\%202017.pdf

Rocamora, A. (2017). En IGES (Ed.), The rise of carbon taxation in France: From environmental protection to low-carbon transition. Japan. Recuperado de: https://pub.iges.or.jp/pub/The-Rise-of-Carbon-Taxation-in-France

Rogissart, L., Postic, S., \& Grimault, J. (2018). La contribution climat énergie en France: fonctionnement, revenus et exonérations. París. Recuperado de: https://www.i4ce. org/wp-core/wp-content/uploads/2018/10/Contribution-Climat-Energie-en-France-VF2-4.pdf

Scharin, H., \& Wallström, J. (2018). The Swedish $\mathrm{CO}_{2}$ tax - an overview. Recuperado de: http://www.enveco.se/wp-content/uploads/2018/03/Anthesis-Enveco-rapport2018-3.-The-Swedish-CO2-tax-an-overview.pdf

Service de l'économie, de l'évaluation et de l'intégration du développement durable. (2017). En Ministère de l'Environnement, de l'Énergie et de la Mer, en Charge des Relations Internationales sur le Climat (Ed.), Fiscalité environnementale. un état del lieux. París. Recuperado de: http://www.google.es/ $\underline{\text { url}}$ ?sa $=t \& r c t=j \& q=\& e s r c=s \&$ source $=$ web\& $\& d=1 \& v e d=2 a h U K E w j a 87 e U 2 K j c A-$ hVLqaQKHeMlB50QFjAAegQIABAC\&url=http\%3A\%2F\%2Fagriculture.gouv. fr\%2Ftelecharger\%2F84785\%3Ftoken\%3D29f327819623f2943788033c1bbc4ab9\&us$\mathrm{g}=\mathrm{AOv}$ Vaw1oZ5gjpZR7Nmni2eTDlEYl

Skou, M. (2010). Europe's experience with carbon taxation. surveys and perspectives integrating environment and society, 3 (2).

Swedish Energy Agency. (2018). Sweden's integrated national energy and climate plan. Draft 2018. Recuperado de: https://www.aktuellhallbarhet.se/wp-content/ uploads/2018/03/energi-och-klimatplan.pdf

Tax Strategy Group. (2017). Energy and environmental taxes. Tax strategy group - TSG 17/08. Department of Finance. Government of Ireland ed. Recuperado de: https:// www.finance.gov.ie/wp-content/uploads/2017/07/TSG-17-08-Environmental-Taxes-Paper-GK.pdf

Tol, R. e. a. (2008). A carbon tax for Ireland. Economic and Social Research Institute Working Paper n. 246.

World Bank Group. (2018). State and trends of carbon pricing 2018. Washington, DC. Recuperado de: https://openknowledge.worldbank.org/bitstream/handle/10986/29687/9781464812927.pdf 